\title{
Does transparency overcome conflicts of interest? Evidence from investment managers and their brokers*
}

\author{
Mark Abrahamson \\ Saïd Business School, Oxford University \\ Tim Jenkinson \\ Saïd Business School, Oxford University and CEPR
}

March 2009

\begin{abstract}
The relationship between investment managers and brokers has been identified by regulators in Europe and the US as a potentially important source of conflicts of interest. Little systematic evidence is available, however, on this complex relationship, which involves trade execution, sell-side research, and a variety of bundled services. This paper reports the outcome of a landmark ruling under the UK Freedom of Information Act, which allowed us to obtain, from UK pension funds, information on commissions, trading activity, payments for research and other variables. We find that following recent regulatory changes in the UK to increase transparency, average commission rates have fallen. However, trading has increased significantly, resulting in total commission payments to brokers more than doubling between 2003 and 2007.
\end{abstract}

JEL classification: G23, G24, G28.

Keywords: Brokerage, Investment Managers, Pension Funds, Commissions.

\footnotetext{
${ }^{*}$ Preliminary version, which will be updated with 2008 data. Please contact the authors before quoting. Comments welcome to mark.abrahamson@sbs.ox.ac.uk or tim.jenkinson@sbs.ox.ac.uk. We are very grateful for funding from the Centre for Corporate Reputation at the Saïd Business School, which supported this research.
} 


\section{Introduction}

One of the central relationships in financial markets is that linking the buy-side and sell-side. Investment managers and brokers sit between the pools of investible funds and the underlying assets. In practice, the relationship between investment managers and brokers is complex, with the latter often providing not just execution of trades but also a bundle of other goods and services including sell-side research, data feeds, trading terminals, and profitable IPO allocations. Such arrangements have been the subject of considerable attention in recent years, focusing on concerns about possible conflicts of interest. But analysis has been constrained by a lack of data - in particular on the economic relationship between investment managers and brokers. In this paper we shine a light into this important part of the financial system by presenting unique data obtained after a protracted case brought under the UK Freedom of Information (FOI) Act. The recent ruling in our favour by the Information Commissioner has resulted in structured information being provided to us by most UK public pension funds regarding the payments made on their behalf by their investment managers to brokers.

This research was really facilitated by an important and wide-ranging investigation into institutional investment that was commissioned by the UK Treasury. This review was chaired by Paul Myners, who presented the report in March 2001. One focus of the report was brokerage commissions, the treatment of which gave rise to a potential conflict of interest between fund managers and their clients. Myners, formerly chairman of Gartmore Investment Management, claimed there was "an a priori case that this system creates an artificial bias for fund managers to have services provided by the sell-side, since the costs for these will not be scrutinised directly by the client" (Myners (2001, p. 11)).

Following from the recommendations in the "Myners report", the Financial Services Authority (FSA) initiated a dialogue with interested parties that began in April 2003 and concluded with a new set of rules in July 2005. ${ }^{1}$ The new rules came into effect on 1 January 2006, although there was a period of transition until 30 June 2006. These rules introduced two important changes: they limited the services that may be bundled into brokerage commissions (only execution and research) and they mandated that fund managers report the source of these commissions to their clients, i.e. how commissions have been split between execution and

\footnotetext{
${ }^{1}$ This dialogue produced a series of consultation papers and policy statements: CP176 (April 2003), PS04/13 (May 2004), PS04/23 (November 2004), CP05/5 (March 2005) and PS05/9 (July 2005).
} 
research.

There has been considerable interest surrounding these regulatory changes, not least from the United States. After much speculation, it appears that the Securities and Exchange Commission (SEC) is favouring a similar disclosure-based solution, though the latest guidance does not specify a particular "disclosure table" format as in the FSA case. As we discuss below, this standard format for reporting was a critical aspect of the reforms which has enabled us to accumulate a consistent set of data. ${ }^{2}$ Fidelity Investments, the third largest mutual fund manager in the United States, made headlines when in October 2005 it announced that it would pay Lehman Brothers separately for brokerage execution and research. Fidelity came to a similar unbundling arrangement with Deutsche Bank in December 2005. Such moves indicated a sentiment that US brokerage commission reforms were inevitable.

There are several related questions that arise from these developments. Firstly, what has been the impact of these regulations and how does this compare with the intended outcomes? Are residual conflicts of interest between investment managers and their clients being acted upon? How has the increased transparency impacted on the provision of sell-side research, both from brokers and third-party research firms? Further, given the findings presented here, is the SEC correct to have adopted FSA-style increased disclosure regulations or should it still be considering more prescriptive unbundling reforms as originally proposed in Myners (2001)?

This paper addresses these questions by performing a comprehensive empirical analysis using a new dataset drawn from tables of disclosure issued by investment managers to UK pension fund trustees under these recent FSA regulations. After controlling for a number of relevant factors, commissions are found to have fallen in recent years as the FSA reforms have become increasingly imminent and understood. At the same time, the proportion spent on research has increased; although this may at first seem to suggest that the reforms have been unsuccessful in reducing conflicts, this effect may well be driven be an increased accuracy and honesty of reporting. However, we also find that trading by investment managers has increased considerably over the period, well in excess of general market movements. So as commissions have fallen, the total payments to brokers have actually risen. This casts doubt on whether the FSA reforms have necessarily improved the value-for-money experienced by investors and

\footnotetext{
${ }^{2}$ For a detailed discussion of the US reforms, see the SEC Interpretive Release S7-09-05 (19 October 2005), the SEC Interpretative Release S7-13-06 (18 July 2006) and, most recently, the SEC-issued Guidance S7-22-08 (30 July 2008).
} 
suggests that there may still be room for regulatory improvement. The present version of the paper employs data until the end of 2007. An additional data gathering exercise is currently being undertaken which will extend the data to include 2008; this will be reflected in an updated version of the paper.

The remainder of this paper is as follows. Section 2 details the reforms introduced by the FSA, outlining the motivations for the changes and briefly discussing the alternatives. Previous survey results and related literature are also presented. Section 3 describes the gory details of the Freedom of Information Act requests, appeals, and the ultimate outcome, and explains how the extensive data collection exercise was conducted. Section 4 introduces the dataset and presents summary statistics. The impact of the FSA reforms on brokerage commissions is examined in Section 5, and the evolution of the research/execution split is considered in Section 6. Section 7 concludes.

\section{Relationships, reforms \& related literature}

It is estimated that around $90 \%$ of all institutional funds by value have segregated fund management arrangements (Oxera 2003). Under such arrangements, the trustees delegate the management of the fund to one or more fund managers who are required to follow a particular investment mandate. These fund managers then execute their trading decisions using one or more brokers. Fund managers are paid a management fee for their services and when choosing a fund manager, trustees are typically rigorous in the negotiation of this fee. In addition, the commissions for trade execution charged by the broker are paid for entirely by the fund and are not borne by the fund manager. Importantly, the trustees generally leave the choice of broker to the fund manager. Anecdotal evidence is supported by survey results that suggest fund managers use execution quality, rather than price, as the main criterion for broker choice (Oxera 2003). These relationships are depicted diagramatically in Figure 1.

The source of the agency problems that worries regulators is as follows. Historically, fund managers have received services in addition to execution in exchange for brokerage commissions. Because the commissions are directly passed on to the client, the fund manager effectively consumes a bundle of services at the fund's expense. If the fund manager served a particular fund exclusively, this arrangement could be efficient provided that (i) the fund could monitor what 


\section{Figure 1: Relationships in investment management}

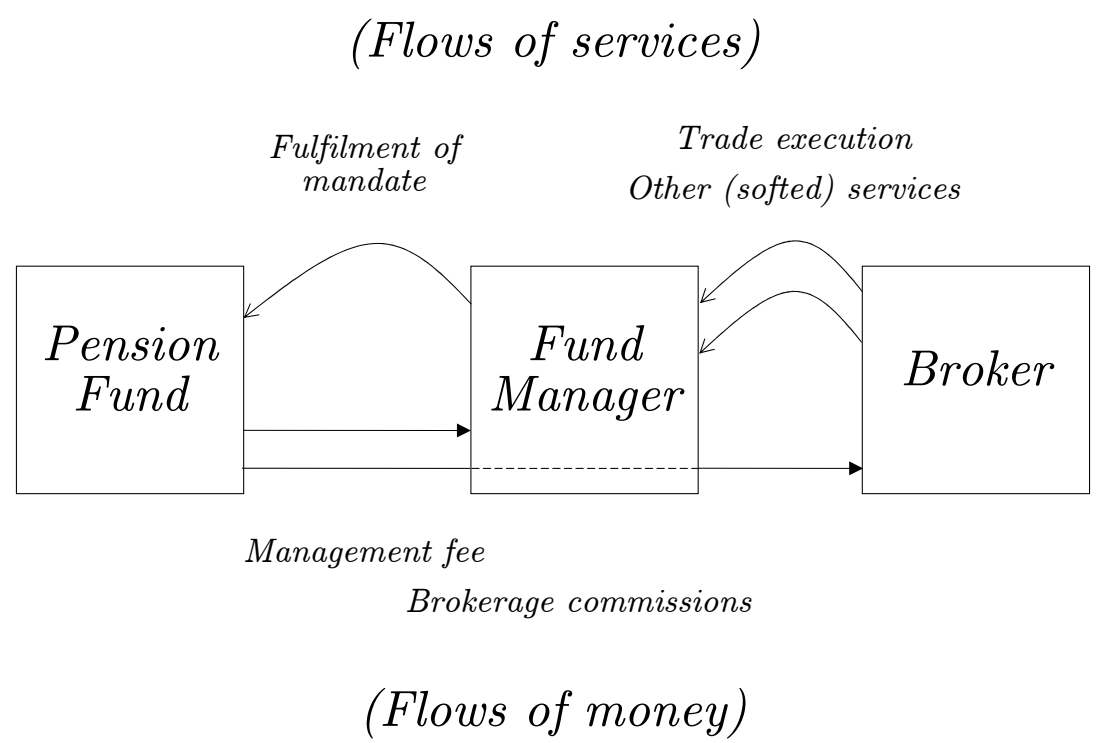

additional services were being provided, and (ii) the performance benefit of the additional services provided to the fund outweighed the implicit cost. However, fund managers typically serve a large portfolio of clients; this means that to the extent these additional services improve the performance of the fund manager, large funds with significant commission expenses effectively subsidise small funds who benefit from the fund manager's superior performance. Alternatively, the conflict of interest hypothesis is that fund managers abuse their relationships with unsophisticated investors by purchasing proportionally more research with their commissions since they are less likely to scrutinise the manager's decisions. The agency problem is compounded because funds have not been able to monitor what services were being provided and, as a result, there has been little incentive for fund managers to ensure that the performance improvement was justified in an implicit cost-benefit analysis. Together, these facts provide a strong case for inefficiency at the expense of the end investor.

There have been two mechanisms for providing these above-mentioned additional services: bundling and soft commissions. In a bundling arrangement the broker provides a bouquet of services to the fund manager in addition to trade execution. ${ }^{3}$ The number of services provided

\footnotetext{
${ }^{3}$ Oxera (2003) suggests that in the UK these services typically include access to analysts, research, conferences, equipment and IPOs.
} 
is often dependent on trade volume. For example, at about the time when the new FSA regulations were being promulgated, a report by Investit, a UK investment management consultancy, suggested that far from considering "research" as a single good, sell-side research is divided into as many as five different categories that will be differentially offered to clients according to their patronage (Byrne, Lawson, Phillipson and Vincent-Silk 2005). ${ }^{4}$ The value of the services contained in the bundled commission is considerable - figures quoted in Oxera (2003) suggest that execution-only trades have commission rates of 5-8 basis points (bp), whereas bundled commission trades could be as high as 13 bp. A subsequent report by Greenwich Associates, an investment management consultancy, presents estimates of comparable magnitude (Greenwich Associates (2006)).

\subsection{Existing literature}

While soft commissions have received some attention in the academic literature, there has been relatively little written about "bundled brokerage" more generally. We consider each in turn.

Although the first rigorous study of soft commissions may be considered to be quite recent (Conrad, Johnson and Wahal (2001)), papers cautioning against the agency problems in soft dollar practices - usually based on survey evidence - have existed for some time (see Blume (1993) as an example from the early 1990s). Conrad et al. (2001) show that the cost of soft dollar research, even after controlling for order characteristics and institution-specific effects, is considerable: they find the incremental cost of using a soft-dollar broker to be $15-18$ bp. ${ }^{5}$ Given that the investor foots this bill, how could such an expensive practice have lasted so long? Schwartz and Steil (2002) claim this is because investors are mainly worried about management fees, a finding based on an expansive survey of chief investment officers and head equity traders at 72 asset management firms, spanning North America, Europe and Australia. This fixation on ex ante costs allows fund managers to have considerable freedom in commissions-bundled commissions in particular - that allow them to "hide" the costs of these ancillary services in returns rather than declaring them as expenses.

Theoretical contributions have been less decisive. On the one hand, Ding (2007) presents

\footnotetext{
${ }^{4}$ Investit separate "research" into the following categories: written research reports, analyst support, production of bespoke research, computer modelling systems and access to corporate management.

${ }^{5}$ The authors use a U.S. dataset, which may partly explain the difference between these results and the Oxera (2003) U.K. (survey) findings.
} 
a model where brokers provide managers with "perks" (i.e. bundled services) in return for trading commissions, but these commissions are entirely paid for by the end-investor who does not benefit from the perks. The manager thus has an incentive to overtrade. Ding shows that the investor can design a contract that aligns incentives between the manager and the investor, but that this will still lead to overtrading. Empirical studies showing fund underperformance as a result of excessive trading are cited as evidence of the "cost" of the conflict of interest inherent in these relationships. If, however, there were to be perfect transparency of perks, Ding (2007) shows that this would reduce the incentives of brokers to provide perks, thereby removing the genesis of the conflict.

On the other hand, Livne and Trueman (2002) and Horan and Johnsen (2008) produce entirely antithetical conclusions. In the Livne and Trueman (2002) model, managers receiving softed services are better informed, which allows them to trade more "aggressively" and thus generate superior returns for their investors. Bundled services thus result in a better fund performance for the investor, which the authors show would be compromised by mandating disclosure of how commissions were spent. For Horan and Johnsen (2008), there is an often overlooked benefit in soft dollar arrangements. Because soft dollar credits for a given period are provided by the broker up-front (i.e. before the manager has requested any trading) and because the credits are valid even if the manager does no trading with the broker during that period, the credits have the effect of guaranteeing best execution by the broker. This is because it is in the broker's interest to provide good service in order to recoup the cost of the soft dollar credits that she has already provided to the manager. In this way, the presence of soft dollars should have the effect of improving fund performance; Horan and Johnsen (2008) provide evidence showing a positive correlation between premium commissions and fund performance.

Of course, papers defending the use of soft commissions or bundled brokerage make the implicit assumption that these ancillary services are inherently valuable and, in particular, more valuable than their alternatives. In other words, research produced by investment banks (sell-side research) must be valued by fund managers; if buy-side research were superior in all respects, then the assumption in Livne and Trueman (2002) that softed services allow managers to be "better" informed would be baseless. Two recent papers shed light on this matter. The first is Groysberg, Healy, Chapman, Shanthikumar and Gui (2007), who find that sell-side 
research is superior to buy-side, even though it is upward biased. The other is Barber, Lehavy and Trueman (2007), who produce evidence that independent research is superior to sell-side. Taken together, these papers suggest a research quality ordering where independent research dominates sell-side research, which in turn dominates buy-side efforts.

If one is to accept these findings, it implies that services bundled in with execution are at least valuable to fund managers. Certainly there has been criticism in the press of sell-side research quality relative to independent research (which would appear to be justified), but if it had been the case that buy-side research were superior to sell-side, it would be prima facie evidence against any form of bundled brokerage. Soft commissions facilitate the purchase of research from (independent) third parties; this at least allows the fund manager to benefit from the research directly, even if the investor's benefit is indirect. The question that remains is whether the conflicts created by bundled brokerage outweigh its potential benefits.

The extensive bundling literature, dating back to Burstein (1960), has only recently considered so-called "information goods": goods which may have high fixed costs but very low or negligible marginal costs of production. In the context of fund management, research-or, at least, written research - constitutes a bundled information good. Bakos and Brynjolfsson (1999) and Geng, Stinchcombe and Whinston (2005) separately consider bundled information goods, producing two relevant insights: firstly, bundling will be profitable for information goods even if they are unrelated (in contrast to regular goods) and, secondly, bundling is optimal provided that the consumer continues to value information goods bought subsequent to the initial purchase. While this says little about conflicts, the findings affirm what has been observed in practice. For instance, it is not unreasonable to assume that fund managers will continue to value research reports from a particular analyst about a particular sector, even if the incremental information (and hence value) is declining over time. In such a situation, bundling this research in with execution forms not only a reasonable but also an optimal contract, according to Geng et al. (2005).

Though it is set in a retail rather than institutional context, Bakos, Lucas, Oh, Simon, Viswanathan and Weber (2005) present a paper closely related to this research. The setting is bundled brokerage, but assessing the impact of introducing a low-cost execution-only competitor to the competitive landscape. Bakos et al. (2005) find that in such circumstances, the 
incumbent is forced to unbundle its offering, but the discount broker produces execution that is relatively inferior. This theoretical prediction mirrors what has taken place in the institutional marketplace as well. To see why, one must recognise that there is a range of quality available even for "execution-only" services: some trades are straightforward "block" trades, whilst others need to be "worked on" - Oxera (2003) impute the difference between complicated and simple trades to be in the region of 2-5 bp. Investment banks now offer bundled brokerage services, but also execution-only brokerage and in support of the Bakos et al. (2005) prediction, their execution services are typically superior to that offered by execution-only, discount brokers.

Despite this, there is little consensus in the literature concerning the net welfare effect of bundling. Research has instead concluded that welfare should be assessed on a case-by-case basis because the outcome is typically sensitive to specifics, a point made more generally for price discrimination in Armstrong (2006).

Similar comments may be made in the context of price transparency. Transparency is relevant here because the UK FSA has chosen to tackle conflicts in fund management by insisting on increased disclosure. However, while it has long been acknowledged that transparency may be a force for increased competition and lower prices, it is also the case that transparency can make it easier for producers to enter into and sustain collusive arrangements (Khün and Vives (1995)). Once again, which of the "consumer" or "producer" transparency effects dominates will depend on the specifics of the case. This literature is not reviewed in detail here, but the more recent theoretical contribution of Schultz (2005) has some applicability for this setting as it is one of the few studies to consider transparency in the context of a heterogeneous product market. Schultz shows that by allowing for differentiated products, the offsetting effects of consumer and producer transparency are tipped in favour of consumer transparency, suggesting it may have a net desirable effect after all. To the extent that this result can be applied to the context at hand, it sheds light on two observations: (1) it supports the FSA's reforms and, (2) more interestingly, it hints at why managers were so reluctant to comply with the freedom of information requests we made, since complying would effectively increase the transparency of commissions. The FSA reforms and the nature of the Disclosure Tables that we obtained are described in the next two sections. 


\section{$2.2 \quad$ FSA reforms}

The FSA reforms were the result of a series of consultations that culminated in the production of Policy Statement 05/9 in July 2005. ${ }^{6}$ In this document the FSA proposed an industry-led regulatory solution that had four implications relevant to the investment management industry. In accordance with the new rules, the FSA hoped to achieve the following:

- Commissions would now only be spent on either "execution" or "research". No other goods or services could be purchased with the commissions. Raw data feeds (like Bloomberg terminals), for example, were no longer a candidate for purchase under the new reforms.

- Disclosure of how commissions were spent by investment managers would be more detailed. In particular, investment managers would have to separate their commission spend into money going to execution and research.

- Ensuring that the incentives of the clients (pension funds) were properly aligned with the service providers (investment managers and brokers) was explicitly stated as an aim.

- The market for research was to become more competitive and less dominated by the brokerage market. The regulatory distinction between bundled services (provided by brokers) and so-called "softed" services was to be removed.

The main changes, then, were tighter definitions of what could be described as "execution" and what constituted "research", the removal of a regulatory distinction between bundled and softed services, and, importantly, the introduction of a new standardised "receipt" for how commissions had been spent.

This receipt has come to be known as an "IMA Disclosure Table" or "Level 2 Disclosure", but was jointly designed by the Investment Management Association (IMA), National Association of Pension Funds (NAPF) and the FSA. The fields in this table are discussed in further detail below. It should be noted, however, there had been disclosure receipts that had existed previously. These older designs varied in their completeness but were often also referred to as "IMA Disclosure Tables" and were similar across fund managers. For instance, they would typically include row entries for each of the top ten brokers and column entries for trading volume, commission spend and sometimes other fields, e.g. stamp duty. The important point is

\footnotetext{
${ }^{6}$ Document URL: http://www.fsa.gov.uk/pubs/policy/ps05_09.pdf.
} 
that there was no explanation in these tables as to how commissions had been spent (execution, research or other). Further, there was no comparison information across funds managed by the investment manager, meaning that clients were unable to determine whether they were getting a "good deal". Nonetheless, there was a considerable amount of valuable information even in the older tables, a matter that is revisited below.

\subsection{The IMA Disclosure Tables}

The new IMA Disclosure Table format was introduced in Appendix 3 of the March 2005 document produced by the Investment Management Association, entitled "Pension Fund Disclosure Code: Second Edition". An in-depth analysis of the fields in this design follows.

Figure 2 provides a pro-forma version of the IMA Disclosure Table, intended to highlight for pension fund trustees how the information contained in the tables could be used to their advantage to help them make more informed decisions.

Beginning from the top left-hand corner, the first block ("Analysis of Trading in period") was borrowed from previous disclosure table designs mentioned in the previous section. The top ten brokers, ordered usually by volume but sometimes by commission, are listed in the far left column. The "Other" row lists the aggregated amounts for the remaining brokers. Columns 2-5 in this block show the volume traded, separating this into trading subject to commissions (e.g. equities) and trading "net" of commission (e.g. bonds and other fixed interest securities). "Full Service" rates refers to cases where there are services beyond execution (e.g. research) "bundled" into the commission fee, whereas "Other" rates relates to "execution-only" trades. One would expect Full Service rates to be higher than Other rates, and the difference could be interpreted as the implied cost of research.

The second block, "Sources of Commission Paid (£)", provides the value of the total commission charged, from which the rate (usually expressed in basis points) can be derived. Though previous designs of the disclosure table usually included the total commission spend, they often did not separate these amounts into Full Service and Other rates. This meant that trustees receiving the tables were unable to gauge what proportion of their commissions was being spent on execution only and how much was going towards other bundled or softed services. This is one of the ways in which the new disclosure design increases transparency. 


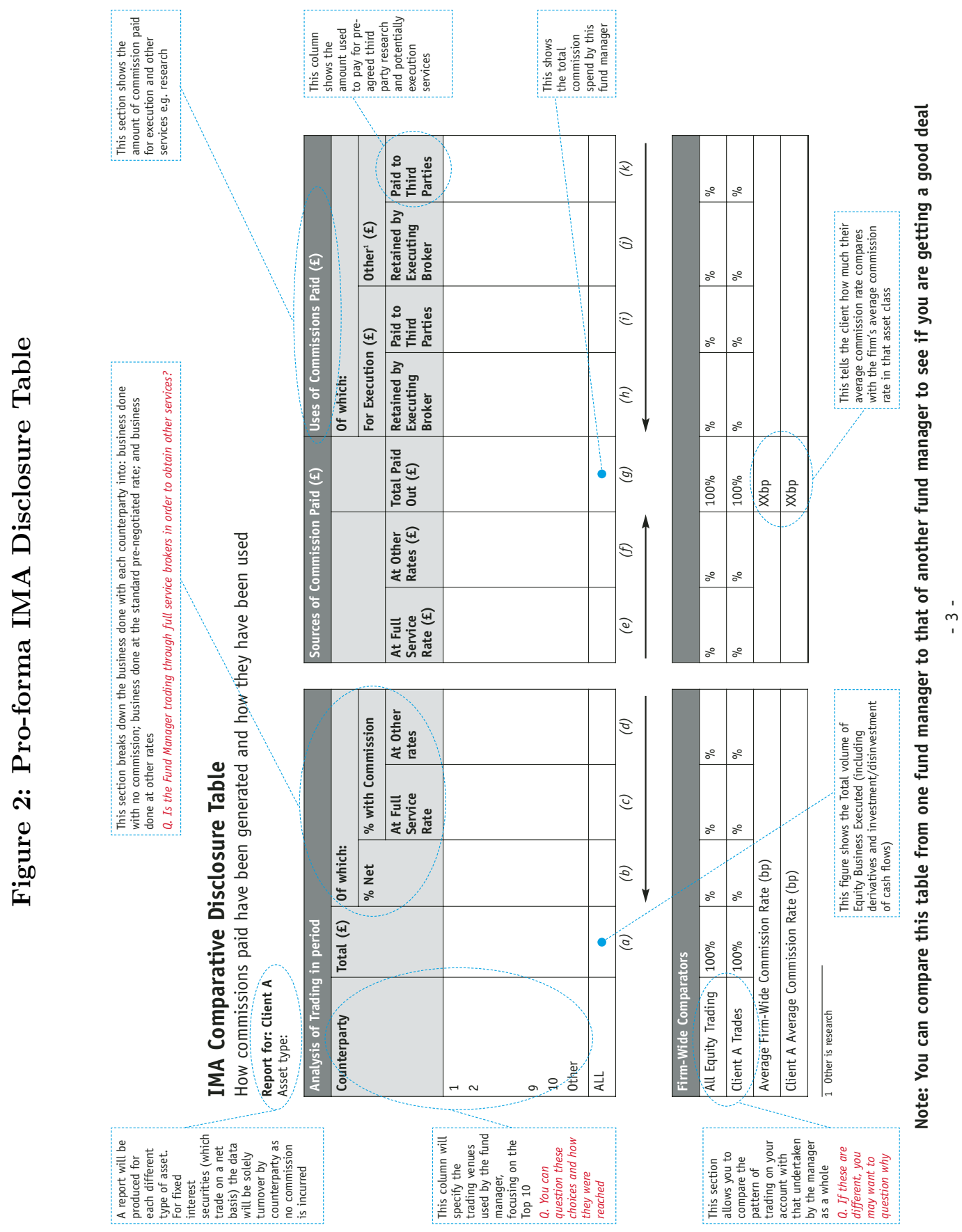


The final block in the top part of the table, "Uses of Commissions Paid (£)", represents part of the crucial innovation associated with the new regulations. In this section, investment managers need to report how they have spent their commissions. To recap for clarity, these are commissions that are charged by the broker to the investment manager for services provided by broker. In accordance with the new regulations, these services may only be either execution or research. However, since these commission charges are passed on directly to the client, but are spent by the investment manager, one could make a strong case that the client should be provided with a receipt detailing how these commissions have been spent. The FSA intended that this block of the disclosure table will address that need for transparency.

The breakdown of commissions into execution and research is further separated into execution/research provided by the executing broker and services provided by third parties. This delineation is relevant for two reasons: (1) it introduces the notion of "commission sharing arrangements" (or CSAs), and (2) it supposedly encourages brokers to use independent companies to provide research to fund managers rather than providing the traditional, sell-side research from the executing broker. Considering each of these in turn, commission sharing arrangements will be reflected in the second column of the block, entitled "For Execution (£): Paid to Third Parties." The idea here is that Broker A may choose to use the services of Broker B for some of the trades in a particular period. This could occur for a number of reasons; for instance, Broker A may recognise that Broker B is able to secure far more favourable rates in, say, a particular emerging market because of its greater presence there. There may even be an understanding that Broker B may similarly use Broker A in an analogous case where Broker A has a competitive advantage. The hope is that the client gets a superior "best execution" by allowing for this flexibility. Early surveys of the investment management community suggested that the use of CSAs would be widely adopted.

The final column of this block, "Other (£): Paid to Third Parties", records the amount of commission that is spent not only on research, but also on research produced by an institution other than the broker handling the execution associated with the row entry. These are the "independent" third party research institutions that the FSA was hoping would be favoured by the changes in their regulations. In fact, they need not be "boutique" research institutions to qualify - all that is required is that the executing broker does not provide the research. In other 
words, it would be possible for Morgan Stanley to be the executing broker whilst using Credit Suisse for research provision.

Arguably the most important addition to the disclosure regime has been the introduction of the blocks appearing below the main section, entitled "Firm-Wide Comparators". This kind of information was never available previously and importantly gives trustees the necessary information to determine whether they are being treated fairly by their investment manager. The first two rows provide aggregate data, expressed in percentages: the first row pertains to all equity trading, across all funds managed by the fund manager; the second row gives the percentages relating to the particular fund to which the table relates. Strictly speaking, the figures reported in the "All Equity Trading" row should relate to equity trading of a comparable type to that being undertaken for the client's fund. For instance, one might expect that commissions would be substantially higher for funds where trading is confined to less liquid securities (e.g. emerging markets). In these cases, the figures presented in the "All Equity Trading" row should be the aggregate percentages for all funds involving similarly illiquid securities.

Comparing the figures in these first two rows would allow clients to see whether there are any important discrepancies in the way their fund is being managed relative to all other funds managed by the same investment manager. For example, they could compare the percentage of trades that are done net of commission versus those that attract commissions. If it transpired that most other funds had a large proportion of net trades whereas for the client's fund there were hardly any at all, that may suggest that the client is getting poor value for money. Similarly, the columns in the "Sources of Commissions Paid $(£)$ " block allow clients to check whether the commission rate is comparable with that being charged to the rest of the manager's clients. A large client may expect that its commission rates should be lower than average commission rates; if this were not the case, the client would now be so informed and would be able to ask the appropriate questions of its fund manager.

The most sensational area for abuse of the client-service provider relationship in fund management has of course been the issue of bundled brokerage. As was mentioned above, it would now be possible for clients to see how their commissions have been spent - the split between execution and research - in a way that was previously impossible. But as far as conflicts of interest are concerned, the more important information is contained in the lower block where the 
comparator percentages are provided. Comparing the pan-fund percentages with the client's percentages in, say, columns "(h)" and "(j)" would allow the client to see whether there are any noteable discrepancies in the treatment of its trades, relative to other the fund manager's other clients. For instance, if the fund manager were spending $70 \%$ of the commissions on research and only $30 \%$ on execution for a client's fund, whereas the figures were reversed for all other clients on average, this would constitute evidence consistent with a conflicted narrative whereby the fund manager receives a disproportionate amount of research at the client's expense.

Finally, the last two rows provide the average commission rate across all trades for the client's fund as well as the average commission rate across all funds managed by the investment manager. This provides a quick overview for the client: if the figures are comparable, then it is likely that the client is being treated "fairly" in comparison to all the other fund manager's clients. Where there is significant divergence, this may not be a sufficient condition for conflicted behaviour or deviation from best practice, but it raises a flag for the trustees to follow up on, should they wish to.

\subsection{Can the trustees be trusted?}

The question of whether trustees wish to follow up on discrepancies is in fact a crucial feature of the revised regulatory package for bundled brokerage as implemented by the FSA. In a discussion with representatives of the FSA it was acknowledged that this was a real concern and that it was potentially the case that many conflicts could continue to go unnoticed due to incompetent or conflicted trustees. Indeed, the success of the regulatory changes is premised on the assumption that the trustees receiving these tables are (1) informed, (2) motivated and (3) unconflicted. It would be heroic to assume that these three conditions are necessarily met in all cases. In smaller funds, particularly, it is quite possible that trustees are not familiar with the dynamics of the investment management industry, making them easy targets for spin from smooth-talking fund managers. Similarly, given that trustees may have numerous other commitments and perceive their role as just checking that extraordinary expenses are not incurred and that a "reasonable" return is generated, they may not be sufficiently motivated to study these tables with the necessary care to ask the right questions. It should be remembered, for instance, that trustees for a particular organisation may be overseeing several "funds" (different asset classes, different 
regions) and so there may be numerous tables requiring review for each period. Checking each of these with the necessary vigilance requires more than a cursory glance. Finally, the possibility that the trustees themselves may be conflicted should not be trivialised. The trustees may be drawn from the investment community itself, where they may have complicated connections to the brokers or fund managers employed by their pension fund. Moreover, they may have incentives to avoid replacing fund managers - either scarcity of time or possibly even perks given to the trustees by the fund managers. Anecdotal evidence suggests that these are real rather than hypothetical concerns.

As has already been discussed, the FSA hoped to encourage the emergence of an independent research industry. This was to be facilitated by allowing fund managers to specify that their research had been bought with the client's commissions from a company other than the executing broker. Since sell-side research had historically often been of a lower quality relative to independent analysis, this would allow fund managers to explain with more confidence to their clients that the research had been (1) carefully sought out and (2) rigorously prepared. The extent to which this has manifested is an empirical matter that is revisited below. However, if the strategy of the FSA were successful in this regard, one would expect that one of the implications would be a reduction in the size of sell-side research departments as funds for research are instead diverted to third party providers.

Another implication that also received some currency at the time of the regulation rollout was the concern that medium-sized brokerage firms would be driven out of the market. Greater scrutiny on how commissions are being spent would have the effect of reducing overall commission levels. This would be because investment managers would substitute research for execution since (1) the definition of what constitutes "research" had been narrowed, and (2) increased transparency would make it more difficult for investment managers to justify so many trades attracting a "full service" commission. This shrinking of research departments and lowering of commissions would mean that brokers would only be able to survive if they had sufficient economies of scale to continue making profits on what would now increasingly be execution-only trades. Medium-sized brokers may have difficulty achieving these economies of scale in the same way that the top investment banks might, making it more difficult for them to remain profitable in this market. Small, boutique brokers would probably be largely unaffected as they typically 
do not provide sell-side research and are also able to charge higher commissions because of their specialisation. Once again, determining the extent of this unintended implication is an empirical matter, though it may be several years before the full effect of these regulations is noticeable in this respect.

\section{Obtaining the data using Freedom of Information legislation}

The main objective for the data collection exercise was to gather a large, representative sample of IMA Disclosure Tables. With such a dataset in hand, it would be possible to test a number of hypotheses relating to conflicts of interest. In addition, a less contentious but a potentially equally valuable contribution would be the chance to obtain a clearer picture of how commissions are spent in fund management. To date, such analyses (see, for example, Oxera (2003) and Oxera (2006)) have been based on questionnaire responses, rather than primary data.

It is seldom a straightforward task to gather financially sensitive information. Because IMA Disclosure Tables reveal not only commission rates but also trading relationships as well as providing powerful comparisons across all clients of a given fund manager, it is not difficult to imagine that there may be some opposition from these parties as regards providing this information.

Furthermore, fund managers enter into confidentiality agreements with their clients. The IMA Disclosure Tables are often accompanied by wording that explicitly prohibits the recipient from sharing the information with third parties. Such confidentiality agreements would be binding in a court of law, making most recipients fearful of producing the information on request. In this section we first briefly explain the Freedom of Information regime that has recently come into force in the UK before describing the protracted process involved in obtaining the data. We explain this process in some detail, as it raised interesting questions relating to whether full transparency to third parties - such as academic researchers - was actually in the interests (ultimately) of investors. These issues are of quite general significance. Furthermore, since the FOI Acts that have been passed in various countries are a potentially valuable way for new data to be obtained, our experience may be useful to future researchers, as well as being interesting in its own right. 


\subsection{The UK Freedom of Information regime}

Freedom of information legislation came into force in the United Kingdom on 1 January 2005. According to this system, anyone has the right to request information held by a so-called "public authority" - including their associated pensions funds - in the UK. It was brought into law in England, Wales and Northern Ireland with the Freedom of Information Act 2000 (FOIA 2000) and then in Scotland with the Freedom of Information (Scotland) Act 2002 (FOISA 2002).

These Acts allow anyone to request any information held by any public authority in the UK. For the purposes of how they have been used in this research, the Acts are reasonably similar and differ only in immaterial ways. ${ }^{7}$ Both Acts define precisely what is meant by a "public authority"; these include, inter alia, city councils, county councils and higher education institutions.

This legislation is particularly powerful and operates as follows. A request for information is made in writing to a public authority. That public authority has twenty days from the receipt of the request to provide the information. In the event that the information cannot be provided within that period, the public authority is bound to contact the requestor and must provide an explanation.

The public authority may not provide the information in certain instances. For instance, it may be that the information is not available, or that it would be expensive to compile the information. In such cases, a fee may be payable before the information is released. The information may also be withheld if it is considered to be exempt in accordance with the Act. If this is the case, the public authority is required to state the exemptions that are being invoked and explain why the requested information falls within the scope of the exemptions. An appeal process, comprising the following stages, can then be instigated: the complainant writes back to the public authority, requesting an internal review of the decision to withhold the information. If this is unsuccessful, the complainant then has the right to appeal to the Information Commissioner (or Scottish Information Commissioner, if appropriate). The Commissioner's decision is, for all intents and purposes, final.

\footnotetext{
${ }^{7}$ The FOIA 2000 and FOISA 2002 can be downloaded in full from http://www.opsi.gov.uk/acts/acts2000/20000036.htm and http://www .itspublicknowledge.info/law/foisa/foisa. asp respectively.
} 


\subsection{The sample of public pension funds}

This project made use of the FOIA 2000 and FOISA 2002 to request IMA Disclosure Tables from public authorities in the United Kingdom. Between May and July 2006, 199 requests were lodged, delineated as follows: 9 requests to authorities connected to central government, 113 to local government authorities (city councils, county councils, London boroughs) and 77 to universities. Details on the exact various parties and how they responded to the FOI requests are available from the authors.

The process began on 22 May 2006, when 10 "trial" letters were sent to local government pension funds. It was decided to adopt a staged process in case there was any ambiguity associated with the wording of the request. In June another 20 requests were sent to local government pension funds and on 20 July 2006 the remaining requests to local government funds and all universities were dispatched.

The responses to the requests were varied. Of the 199 initial requests, only 16 were unambiguously positive, providing the information as requested. Some 66 public authorities invoked exemptions; this is described in further detail below. Responses from the remaining authorities, which constitute more than half of the original sample, fell into one of the following categories:

1. Not applicable - for instance, the pension fund "associated" with the public authority is not managed by that authority (this constituted the majority of this sub-sample).

2. Not available - the pension fund expects to be receiving IMA Disclosure Tables but is still waiting for them to be provided.

3. No response.

The exemptions invoked by the public authorities almost all fell into two categories: exemptions relating to confidentiality and exemptions relating to commercial sensitivity. Specifically, authorities subject to the FOIA 2000 invoked, in the main, Section 41 ("Information provided in confidence") and/or Section 43(2) ("Commercial interests"). Analogously, authorities subject to the FOISA 2002 invoked Section 36 ("Confidentiality") and/or Section 33(1)(b) ("Commercial interests and the economy").

Although most of the authorities refusing to supply the information cited confidentiality or commercial interests, the reasons provided varied considerably. When claiming that the 
information was exempt due to commercial interests, some authorities claimed it was their commercial interest that was at stake, whilst others claimed it was the commercial interests of the investment managers and/or their associated brokers. Some argued that by sharing the information the fund's profitability would be undermined due to an increase in costs. This was sometimes linked to the suggestion that fund managers would not be able to negotiate "good rates" if information relating to commission charges was made public. Other authorities were concerned about the fund manager's investment strategy being divulged or that fund managers would cease to provide disclosure tables.

During this process of data collection, which took place over a number of months, there were two noteworthy observations. One was that many authorities contacted their fund managers as a courtesy to inform them that they had received the request. When this happened, it seemed that the fund managers used scare tactics to stop the authority from providing the information. Documentary evidence of this may be seen for instance in the attachment drafted by the lawyers of Baillie Gifford to Fife Council, which details the alleged repercussions of providing the requested information for this project. Numerous telephone calls pointed to this observation as well-several authorities seemed willing to provide the information when asked but were nervous of the potential backlash from their investment managers (e.g. calls in July and August 2006 to representatives of Scottish Borders and London Borough of Newham). A call from Baring Asset Management in July 2006 was the only direct contact between this project and fund managers relating to the request, but the questions asked (purpose of request, would identity of Baring be revealed, would the findings be publically available) mirrored the concerns that were listed in the responses from the authorities. ${ }^{8}$

The other observation was that the various public authorities began contacting one another to consider jointly how to handle this request. As evidence of this one might note that the "successful" requests tended generally to be those that were sent in the earlier batches, suggesting that as more and more authorities received requests they increasingly came to a decision not to provide the information. In addition, the phrasing of reasons provided by the authorities for invoking the exemptions was, in several cases, identical. However, the surest indication of this came on 21 September 2006 in a call to London Borough of Barnet Superannuation Fund to

\footnotetext{
${ }^{8}$ It should be noted that, in terms of the FOIA 2000 and FOISA 2002, requestors are not required to indicate the purpose of the request.
} 
ascertain why there had been no response to the FOI request. The person contacted had not actually seen our original request but was familiar with the details because he had been copied in on emails sent to a number of councils discussing how to respond to it.

\subsection{Initial appeals}

The authorities that invoked exemptions indicated that it would be possible to request a review of their decisions using the appeal process laid out in the Acts discussed above. Such reviews are handled internally by the authority, though it is customary for the case to be handled by parties not associated with the original decision. Different authorities approach this process differently: some convene a special committee to discuss the appeal, others delegate the decision to another officer in their information department.

61 bespoke requests for review were sent to exemption-invoking authorities. Appeals were not sent to the remaining five authorities either because it was judged that the appeal process would be necessarily unsuccessful or because the case was still being considered by the authority.

Although each request for review was different, there were a number of key arguments put forward in favour of disclosure. Apart from noting that there had been full disclosure compliance by certain public authorities who were apparently in the same position, it was strongly argued that it was in the public interest for this research project to go forward. In particular, for the FOIA 2000, it was noted that Section $42(3)$ is subject to a public interest test: does serving the public interest by disclosing the information outweigh the potentially deleterious consequences associated with the commercial sensitivity surrounding the information? In addition, Section 41 is subject to a public interest defence: attention was drawn to the fact that the Department for Constitutional Affairs's Full Exemptions Guidance on Section 41 (paragraph 3.4.5) provides examples of where there may be a public interest in the disclosure of confidential information. These include: (1) information revealing misconduct/mismanagement of public funds and (2) information which shows that a particular public contract is bad value for money. Similar arguments can be made with reference to the FOISA $2002 .^{9}$

It was pointed out that the research project associated with the request was principally concerned with ascertaining whether the FSA's revised regulations have had any significant impact. This being the case, it was argued that only through the kind of impartial analysis that

\footnotetext{
${ }^{9}$ See the Scottish Information Commissioner's Briefings on Exemptions in the Act (Section 36), paragraph 5.
} 
this research offers could investors ever know with any certainty whether investment managers and brokers are acting in their best interests. Provided that these parties were acting in best interests of their clients, there seemed to be no reason to suggest that their commercial interest could or would be harmed by this research.

There were 48 responses to the 61 requests for review. Of these 48 responses, nearly all (44) upheld the original decision not to provide any information. The remaining four either reversed their decision entirely or provided partial disclosure.

At this stage two options remained open for obtaining additional data: (1) to request more recent tables from authorities who provided information in the first round of requests and (2) to file a final appeal with the Information Commissioner. Both avenues were pursued and are described in the following sections.

\subsection{Further requests}

Given that the data collection exercise had thus far yielded a limited number of IMA Disclosure Tables, it was decided to lodge additional requests with certain authorities. These authorities came from two categories: (1) authorities who had complied with the original request and had provided usable data, and (2) authorities who had indicated a willingness to comply with the original request, but - for whatever reason — had not been able to do so (typically because they had not yet received IMA Disclosure Tables)..$^{10}$

Sixteen authorities were contacted in this round; only 5 authorities provided the requested information. Of particular interest was the fact that some authorities who had previously given information, now refused to do so by invoking exemptions contained within the Act. Shropshire County Council was concerned that if they complied with the request (against the wishes of their fund managers), this would "damage the potential for growth by limiting the number of Fund Managers prepared to contract with us." Cardiff County Council indicated that they had not initially expected that similar requests would be made annually, from which "changes in brokers etc. could be monitored and used to identify trends in trading activity."

Whilst it is not at all obvious why the monitoring of broker changes should be detrimental to any particular party, what is more curious is Cardiff's position that the requested information

\footnotetext{
${ }^{10}$ Some of the authorities who had complied with the original request were members of pooled funds. For some of these, disclosures were not in "IMA" form and did not contain commissions data. These authorities were not contacted again.
} 
should be of no interest to the public or the fund's investors. Cardiff claimed that it does not matter to an investor "if a particular fund manager pays more in fees and charges in order to obtain a higher gross investment return, or visa versa." This comment reveals an ignorance (intentional or unintentional) of the potential conflicts of interest. The issue here is not whether a fund has outperformed a benchmark, the issue is whether the fund could have performed better if conflicts had been managed. Investors should care about how commissions are being allocated between research and trading because this may influence the performance of the fund. Similarly, investors should care about whether the average commission charge is higher or lower than for other funds of their fund manager. In a bull market, a fund may outperform but investors may still be receiving a bad deal if their fund manager is acting on his conflicts of interest. Only by reviewing IMA Disclosure Tables can investors guard against this-information on gross investment return alone will be insufficient.

Finally, there is something of an interesting story in the negative, non-exemption-invoking responses. Consider, for instance, Powys County Council Pension Fund. They were initially contacted on 20 July 2006 with the standard request for IMA Disclosure Tables. They provided a table from AXA Rosenberg, as requested, on 4 August 2006. That table contained information pertaining to the quarter ending 30 June 2006. However, when contacted almost a year later, on 19 July 2007, Powys responded saying that they had not received any further tables subsequent to the initial request. Combine this observation with the response from London Borough of Brent. Quickly responding to the 19 July 2007 request, the Head of Exchequer and Investments at Brent Council, Martin Spriggs, wrote: "Thank you for your letter requesting IMA disclosure tables to March 2007. As these are largely irrelevant to me, I have not sought details from my managers for this year." In response to the initial 2006 request, Brent Council, via Martin Spriggs, had provided disclosure tables from Bank of Ireland Asset Management, produced at quarterly intervals from July 2005 until April 2006, indicating that the Council had been receiving disclosure tables for some time.

If it is possible that these two anecdotes are not examples of isolated practice, they hint at a rather disturbing pattern. The FSA's solution to conflicts of interest in investment management has been to increase disclosure. However, if investors (or, in their place, trustees) are not scrutinising this information - whether it be due to lack of provision on the part of fund managers 
or the perceived irrelevance of the information by the trustees/investors themselves - the new regulations are not going to have their desired effect. In discussions held with FSA representatives, this possibility was raised as a genuine concern; these subsequent responses from Powys and Brent suggest the FSA may have cause to worry. Transparency may actually be reducing disclosure.

\subsection{Final appeals}

Given the rather disappointing response to the initial appeals, there remained one final recourse in law: appealling directly to the Information Commissioner and Scottish Information Commissioner. In accordance with the Acts, following an unsuccessful appeal to the authority, the decision can be reviewed by the information commissioners, whose decision is final.

Having contacted the Information Commissioner in November 2006, it appeared that this case was unprecendented in the sense that there had been identical requests sent to multiple public authorities. However, rather than lodging a single complaint from a given public authority, it was suggested that it would be better to include all the authorities in this appeal, and hence it would be best to wait until all responses had been received.

Letters of appeal were sent to the Information Commissioner and the Scottish Information Commssioner on 23 March 2007. The letters outlined the regulatory context and explained the information contained within IMA Disclosure Tables. The specifics of the request were detailed and the necessary supporting documentation (copies of all correspondence with the public authorities) was included in the packages. In addition to reiterating the main arguments surrounding the public interest for providing the information, there was also reference to the apparent precedent of a recent case involving the West Midlands Pension Fund and Wolverhampton City Council, which had requested information about private equity investments.

This case, which was resolved by the Information Commissioner on 28 September 2006 (case reference: FS50065853), found in favour of the complainant. The request associated with this study shared many similarities with the Wolverhampton case: both involved requests for investment-related information associated with a pension fund aligned to a public authority. In both cases, the information had been refused on the grounds of confidentiality (Section 41) and commercial interest (Section 43(2)) and then subsequently overturned by the Information 
Commissioner. It can be and was argued that the information requested in the Wolverhampton case was more commercially sensitive than that requested for this project.

In our case, the Information Commissioner for England, Wales and Northern Ireland served the first of its Decision Notices on 4 February 2008, finding in favour of the complainant (i.e. this research project). In a 33-page detailed analysis of the arguments presented by all parties, the Commissioner ruled that the public authority-Tameside Metropolitan Borough, which was used as the "lead case" - was required to "disclose all of the information from the disclosure tables other than the names of brokers concerned and the market areas named in each table where applicable." Furthermore, the public authority was required to make the relevant disclosure within 35 calendar days from the date of the notice. The Commissioner has subsequently continued to serve Decision Notices with the identical finding to the remaining public authorities. These Decision Notices are available for download from http://www.ico.gov.uk/tools_and_resources/decision_notices.aspx.

The implications of this favourable ruling for this research are considerable. Whereas the data sample originally collected is relatively small, the tables that became available in the wake of the ruling allow for wholly representative and powerful analysis. The Information Commissioner did, however, stipulate that tables provided would have the broker identity and geography removed.

Cases that fell under the auspices of the Scottish Information Commissioner were handled somewhat differently: because the Information Commissioner for England and Wales had already served Decision Notices as described above, the Scottish Information Commissioner was eager to come to a series of negotiated settlements in exchange for a withdrawal of the final appeal lodged in March 2007. In the England, Wales and Northern Ireland cases, some authorities provided data exactly as per the original request (i.e. tables that had been received up until mid-2006) but others provided data right up until the end of 2007. However, because of the opportunity for negotiation with the public authorities through the Scottish Information Commissioner, it was possible to obtain recent as well as older data for all Scottish public authorities. Accordingly, the final appeal lodged with the Scottish Information Commissioner was finally withdrawn on 23 June 2008. 


\section{Data}

The result of the 2-year battle to obtain data was a flood of IMA Disclosure Tables from public authorities. These are rich in information as they contain not only information about the public authority's fund management for the reporting period, but also information about the fund manager's whole operation during the reporting period. As described in Section 2.3, these variables include, inter alia, the commission rate and the split between research and trading.

Recall that IMA Disclosure Tables contain not only the aggregated information for the public authority during the reporting period, but also a breakdown of turnover, commissions and so on by broker. However, as was mentioned in the previous section, tables received subsequent to the decisions taken by the information commissioners have had the broker identities redacted. In addition, where a geographic focus was indicated by the fund manager (and only a handful of fund managers do this), that information was redacted as well. Given that the primary benefit of the granularity provided by the broker breakdown is tied up with the identities of the brokers, it was decided to capture only the aggregated data for each fund, along with the fund manager comparators. For the empirical analyses undertaken in this paper, therefore, each "observation" represents a single IMA Disclosure Table from a particular period, managed by a particular fund manager and belonging to a particular public authority, e.g. second quarter 2006, managed by Baillie Gifford \& Co., belonging to Oxfordshire County Council.

Tables received from public authorities were typically provided in hardcopy format, though some authorities emailed the information in electronic form (typically scanned into Portable Document Format). There is some variance in the format of the earlier tables since some of the tables provided by the authorities referred to periods prior to the introduction of the new IMA Disclosure Table format. Whereas the Freedom of Information requests sent to the public authorities had been as clear as possible in making reference to the new disclosure code and, in addition, included a pro-forma copy of the new format, respondents sent tables that included periods prior to the new design.

Whilst it is of benefit to the study to have a longer time series of data, the format of these earlier table versions (see Section 2.2 for further discussion on this) differed by fund manager. Consequently, there is considerable cross-sectional variance in the information available across fund managers, though over time it seems fund managers tended to stick to a particular format. 
For instance, only Legal \& General specifies the percentage of internally and externally crossed trades. Prior to mid-2006, UBS Global Asset Management distinguished between Directed Commission, Hard Commission and Soft Commission, whereas most other investment managers do not. However, although there are differences in the formats adopted by different investment managers in the past, managers now appear to be adhering to the layout of the "new" design; consequently, there is little variation in the format of the more recent tables.

The consequence of these discrepancies is a somewhat fragmented dataset. Most of the tables received are of the new design, which means there are sufficient observations to perform a rigorous analysis on the split between research and trading. However, such findings can only pertain to the period from 2005 onwards (when some managers began adopting the new format), whereas questions relating to commission rates more generally have data stretching back to the first quarter of 2003.

Perhaps most strikingly, however, is the extraordinary dominance of one fund manager in the sample. Capital International accounts for one third of the observations. One reason for this is that Capital produces different tables for different geographic mandates, though it is not generally known to which geography a table relates due to the redaction. However, other fund managers also do this (e.g. AllianceBernstein and Baillie Gifford \& Co.) but they do not command such a large proportion of the sample. It may simply be that Capital has been especially successful in securing business from public authorities. Whatever the reason, it is important to take account of this feature. This is especially necessary since Capital, unlike any other fund manager, reports exactly the same split between research and trading for all its tables. That is, Capital reports that it has spent " $>95 \%$ " on execution and " $<5 \%$ " on research. This is a particulary low proportion to be spending on research and, in addition, does not vary across time or fund for Capital.

Another aspect of the dataset that deserves comment is the presence of so-called "pooled" tables. Whereas more than four fifths of the sample is constituted by "bespoke" tables, i.e. tables prepared by the fund manager for a particular public authority having been invested in accordance with that particular authority's mandate, there are also a number of tables that refer to investment vehicles managed by the fund manager that are sold to several investors. As one might expect, these pooled funds are typically larger and are quite possibly subject to less 
meticulous scrutiny than bespoke tables, which public authorities will be especially interested in. Again, correcting for these effects will be desirable in a complete analysis.

Fund managers report the currency used for values such as turnover volume and commission cost. Although it is not possible to determine the geographic mandate used for each fund in the sample as described above, one can be reasonably certain that tables reporting a currency other than pound sterling are likely to be covering a foreign geography. Given that foreign geographies are generally associated with higher commission rates (emerging market rates, for instance, are frequently double that used in developed markets), including these tables is likely to bias the commission rates upward. Accordingly, tables reporting values in currencies other than GBP have been excluded. Similarly, tables reporting aggregate fund commission rates in excess of 50 basis points are excluded as these not only bias the sample but are almost certainly the product of reporting errors.

The final sample used in the main body of analysis therefore comprises some 1178 IMA Disclosure Tables, covering the 2003-2007 (inclusive) period, spanning 54 public authorities in the United Kingdom and representing 36 fund managers. As noted earlier, a subsequent version of this paper will include information for 2008 .

\subsection{Variables and coding}

Having captured the values from the IMA Disclosure Table originals as discussed above, the dataset is parameterised and coded into variables. ${ }^{11}$ In this section, the specifications for variables used in the empirical body of the paper are described.

The empirical analysis that follows will be primarily concentrated on two components: commission rates and the split between research and trading. Accordingly, one of the crucial variables used in the study is commclient, the average rate of commission charged for all trades during the reporting period to which an IMA Disclosure Table relates. This variable is expressed as a percentage, so that - for example - a value of 0.01 represents 1 basis point. Similarly, commmgr reports the average rate of commission charged to all clients by a fund manager for the period to which a particular IMA Disclosure Table relates. An example may be helpful here: Somerset County Council has an IMA Disclosure Table managed by UBS Global

\footnotetext{
${ }^{11}$ Given that some fields were not recorded in the data capture exercise, it remains possible for future analyses not only to code variables differently but also to add additional fields as only fields pertinent to the questions raised for this study were captured.
} 
Asset Management for the third quarter of 2007. In this instance, commmgr will report the average commission rate charged by UBS Global Asset Management to all its clients (including Somerset County Council) during the third quarter of $2007 .^{12}$

The split between research and trading is captured by the rschclient variable. This variable is defined as the proportion spent on services other than execution services provided by the executing broker. In theory, this includes not only research services provided by the broker and third parties but also execution provided by third parties. In practice, however, virtually no tables reported positive values for execution services being provided by third parties (so-called "commission-sharing arrangements" or CSAs). Consequently rschclient may be interpreted as being the proportion of commissions spent on research, provided either by the executing broker or by third parties. As with commission rates, there are firm-wide comparators for the research/trading split, which are once again sometimes mandate-specific rather than truly firmwide. This split is captured by rschmgr, the proportion spent on services other than execution services provided by the executing broker, across all funds managed by the fund manager for the reporting period associated with a particular IMA Disclosure Table.

IMA Disclosure Tables also include trading turnover volume for the period. In order to correct for the fact that not all tables use the same reporting period (most use quarterly reporting, but some use semi-annual or even annual reporting), the variable turnover is constructed by first dividing turnover (expressed in GBP) by the number of days in the reporting period and then taking the natural $\log$ of this value. Importantly, turnover includes turnover that is charged "net" of commission. Trades will be charged net of commission for fixed income securities, but also for some equities trading, for instance in the case of so-called "block" trades. In order to correct for this a dummy variable (net) is introduced, which reports a value of 1 if there are net trades in the table and 0 otherwise.

Finally, additional dummy variables are created for pooled tables (pooled is 1 if the table relates to a pooled fund and 0 for bespoke funds) and for tables where there are payments to third parties for research (3rdparty takes a value of 1 for these observations and 0 otherwise).

\footnotetext{
${ }^{12}$ Some fund managers provide a single firm-wide commission rate for this field, whereas other fund managers will provide an average commission rate for funds with a similar or equivalent mandate (e.g. UK Equity). It is not possible to assess which definition is being used for each fund manager, however, so there is no correction for this; one would expect that commmgr will be closer to commclient than if genuine "firm-wide" commission rates were reported by all fund managers.
} 


\section{Figure 3: Commissions over time}

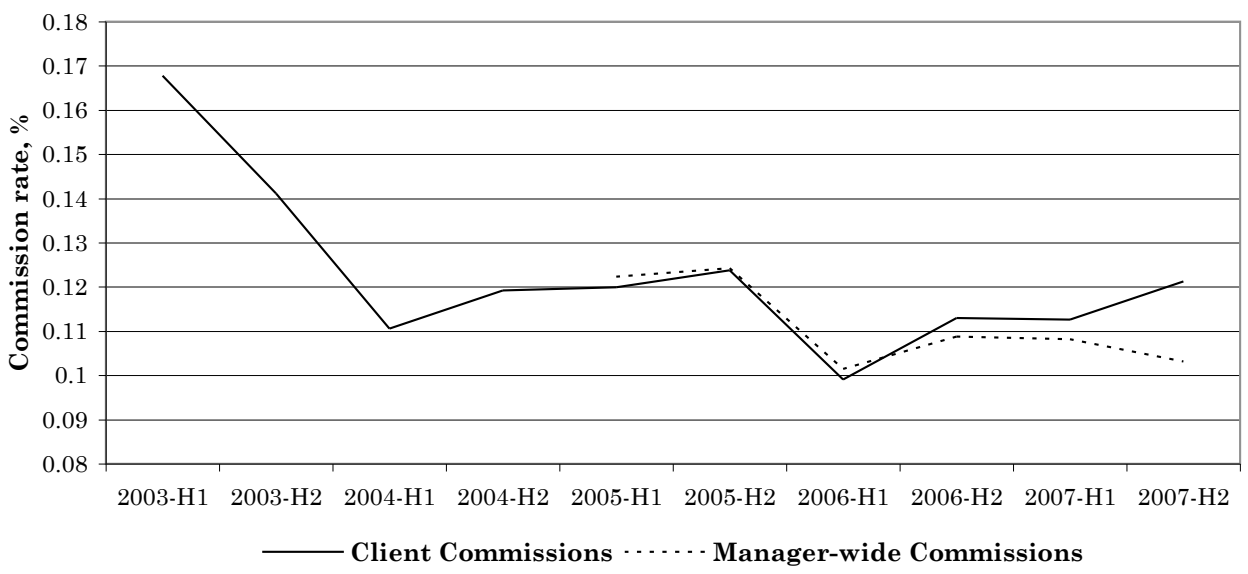

\subsection{Summary statistics}

As indicated previously, the principal interest in this study is to assess whether commission rates and the split between research and execution have changed since the introduction of the FSA reforms. An obvious starting point is to plot the evolution of these variables over time to see whether there is any discernable shift. Naturally there will be a number of factors that will not be controlled for in these univariate plots, which motivates the more comprehensive analysis that is to follow. In this section, therefore, comprehensive summary statistics of relevant variables are presented, alongside graphical representations.

\subsubsection{Commission rates}

Turning first to commission rates, plots of commclient and commmgr are graphed in Figure 3.

There are three noteworthy features in this graph. To begin, it is immediately apparent that client commissions (commclient) are remarkably close to manager-wide commissions (commmgr). Though this is perhaps not surprising, it is also not necessarily what one might have expected. The implication is that a considerable amount of the variation in commission rate that a public authority pays is captured by the fund manager it chooses to employ. Second, it would seem that, relative to 2003, commission rates seem to have fallen somewhat. This certainly coincides with the period in which the FSA reforms were introduced, but it would be premature to make any inferences regarding regulation efficacy at this stage. Finally, the exception to the general 
tracking of client commissions by manager-wide commissions comes in the second half of 2007; this is, however, solely the influence of a single manager (Lazard) which constitutes nearly $30 \%$ of that period's sample and has an unusually high average commission rate of $16 \mathrm{bp}$ for the second half of 2007. In summary, there is weak evidence from this graph that commissions may have fallen; the multivariate analysis that follows will adjudicate this more reliably.

\subsubsection{Turnover and total commission spend}

Before turning to the split between research and execution, it is worth considering the actual amount of money traded and spent over the sample period for the average fund. Brokers employed by fund managers can of course earn higher commissions by either raising commission rates, raising turnover, or both. Though much of the discussion has rightly focused on commission rates, it is worth briefly pausing to see whether turnover and/or pounds spent on commission have changed considerably during the sample period. Figure 4 plots turnover and the value of commissions by year for the sample period. Specifically, it plots the average turnover and commission spent per fund per year for non-pooled (i.e. bespoke) funds only. The values for pooled funds are given below in Table 1 but are excluded here because the pattern for pooled funds is not representative of the bespoke funds and swamps the latter effect. Bespoke funds are the main focus in this analysis for two principal reasons: (1) nearly 1000 of the 1178 tables are bespoke tables, making this finding more reliable; and (2) while pooled funds tend to be off-the-shelf products sold by investment managers that public authorities may or may not elect to purchase, bespoke tables are what public authorities really care about - the IMA Disclosure Table solution of increased transparency relates primarily to a bespoke fund concern as the associated public authority is the only party to interrogate the fund manager's decisions.

To begin, note the scale: bespoke funds in 2007 averaged a turnover volume of nearly $£ 450$ million each. To put this in perspective, consider that commission rates in 2007 averaged about 11 basis points: this means that the average public authority in the dataset (e.g. a city council in the United Kingdom) spent about half a million pounds on commissions, with many spending much more than this. When a reduction of a single basis point translates into a saving equivalent to $£ 50000$ on average for each public authority in the UK, the motivation for reducing conflicts seems real indeed. 


\section{Figure 4: Turnover and commissions over time, pooled funds excluded}

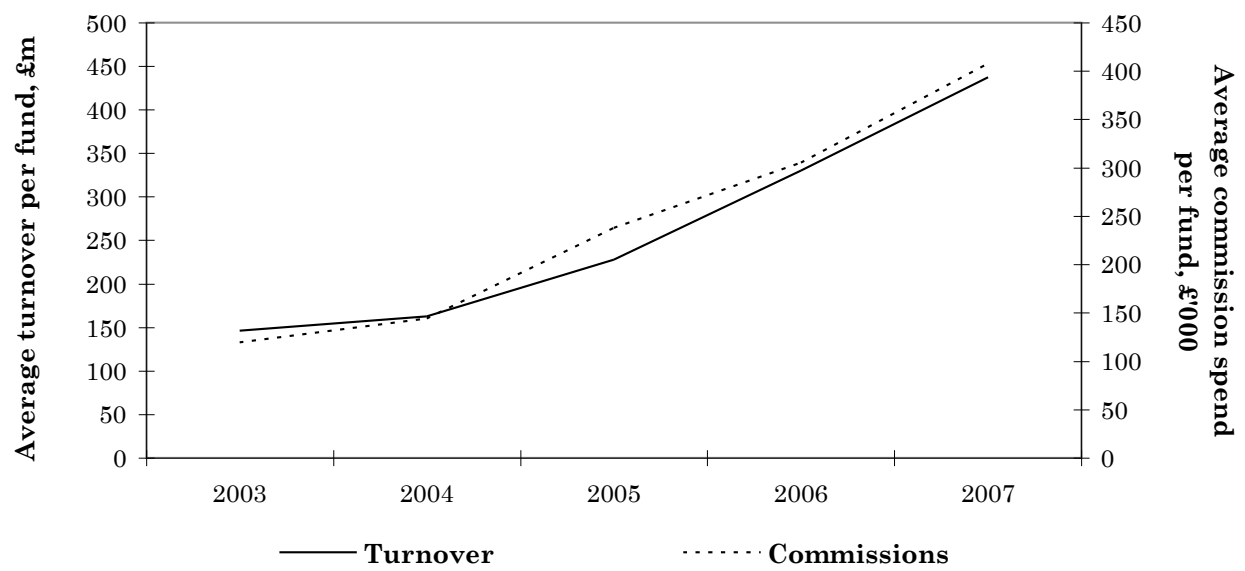

However, though the scale is impressive, the remarkable feature of this figure is the trend. Since 2003, turnover has roughly increased threefold, from $£ 150$ million to £450 million, but the amount spent on commissions has followed this trend very closely, rising from about $£ 120$ 000 in 2003 to $£ 400000$ in $2007 .{ }^{13}$ Before drawing any conclusions it should be noted that the ratio of commissions to turnover is not exactly the commission rate as there are net trades in the turnover figure. However, these typically form a small proportion (less than 10\%) of turnover. Furthermore, it should be noted that there was a steady transition from a bear to bull market over the 2003-2007 period, with the FTSE 100 index climbing by nearly $70 \%$ over the period. Nonetheless, given that the turnover increase is well in excess of $100 \%$, rising share prices cannot fully account for the extent of this turnover trend.

The close relationhip between commissions and turnover in Figure 4 does suggest that the commission rate has been relatively stable over the period. However, as indicated above, a regression analysis is required to control for relevant compositional factors that may be influencing the univariate outcome. Nonetheless, even if after controlling for relevant factors it is found that commission rates have fallen, the sheer magnitude of the increase in turnover recorded in this figure makes it difficult to believe that public authorities could possibly be getting a better deal in 2007 than they were getting in 2003 or even 2005.

\footnotetext{
${ }^{13}$ Removing Capital Interational from the sample generates the same pattern but with lower figures: approximate figures show turnover increasing from $£ 150 \mathrm{~m}$ to $£ 300 \mathrm{~m}$ while commissions rise from $£ 120 \mathrm{k}$ to $£ 320 \mathrm{k}$. See Table 1 for more details.
} 
Figure 5: Proportion spent on research over time

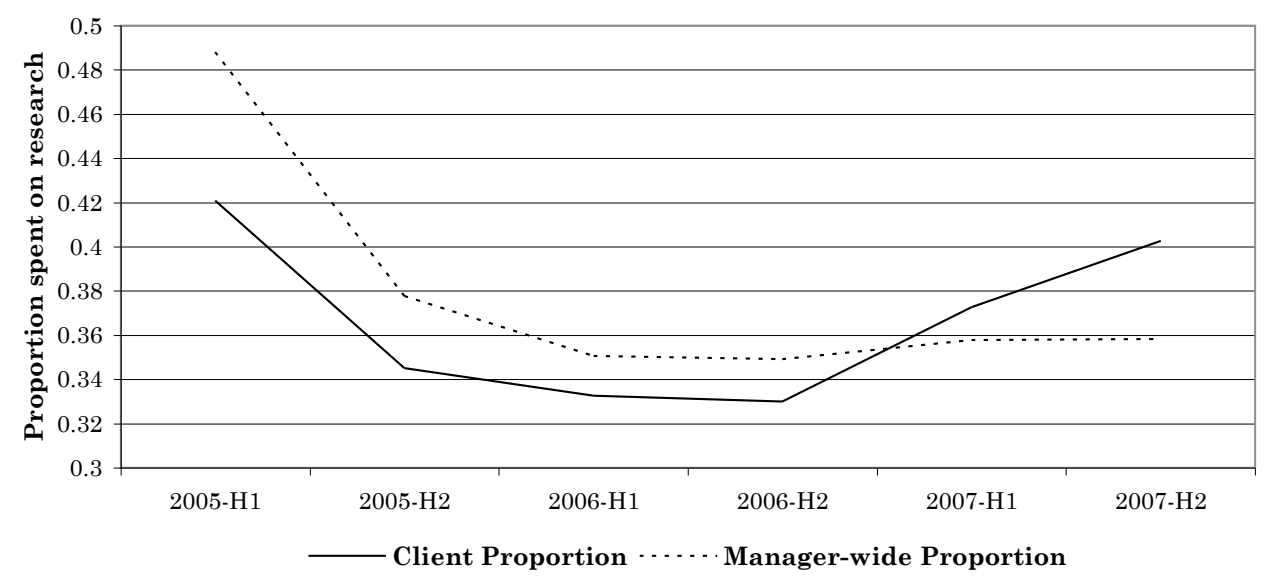

That bespoke fund turnover has increased so dramatically over the period is concerning as it does hint at a churning hypothesis: in the event that there was downward pressure on commission rates due to transparency, brokers may demand increased turnover from fund managers to maintain a comparable income (and these managers are the very institutional investors who benefit from, say, preferential IPO allocations). The robustness of the relationship between turnover and commission rates is revisited below in Section 5.1 as it remains possible that the extraordinary pattern in Figure 4 is due to compositional effects. In the meantime, it is worth remembering that regardless of how commission rates have evolved, average turnover for bespoke funds appears to have increased year-on-year at an astonishing rate.

\subsubsection{Split between research and execution}

The split between execution and research is captured in Figure 5, which includes values from the first half of 2005 when fund managers first began using the IMA Disclosure Table format. ${ }^{14}$ This graph is plotted using values that exclude Capital International tables as there is no variation over time or across funds in the split for this fund manager.

To begin, note the level. Most values are concentrated between 0.3 and 0.4 , so the average manager spends more than $30 \%$ of its client's money on research instead of execution. Of course it is true that this research allows managers to make better investment decisions on

\footnotetext{
${ }^{14}$ It is noteworthy that although investment managers were not required to adopt the new IMA Disclosure Table format until the 1st of July 2006, many had already moved over to the new format in 2005 .
} 
behalf of their clients, as discussed earlier, however it is important to see that proportion spent on research is not trivial.

As in the case of commissions, it seems that the evolution of the split is very similar between client specific and manager-wide proportions. However, it is not immediately apparent what the pattern here is, if there is on at all. Until the end of 2006, for instance, it appears that the proportion spent on research is declining, but from 2007 onwards it seems to increase. Public authorities appear to be paying for less research than on average until the end of 2006, but this is reversed for 2007 onwards. Again, a multivariate analysis is called for to determine whether there is a true underlying pattern at work.

For completeness, a table of summary statistics is presented in Table 1. Much of what is detailed in this table has been discussed already with reference to the figures above, though it is worth drawing attention to a few features.

The table separates statistics into values pertaining to the full sample and observations that do not include tables from Capital International. As mentioned before, Capital accounts for one third of the sample and it will be important to know that key results are not being driven by their presence. For example, recall that the split between research and execution is constant across all Capital tables, and has an unusually low proportion devoted to research. Particularly for analyses relating to that split, therefore, it will be necessary to consider not only the full sample but also a sample that excludes Capital International tables. It is significant, though, that the pattern of bespoke turnover increasing over time is present whether or not one includes Capital International, even if the 2007 value is considerably lower.

It is also clear from this table that there are notably fewer observations for 2003 and 2004 than there are for the rest of the period. This is understandable, given that the requests were specifically for IMA Disclosure Tables as per the revised regulations. However it does mean that earlier values will be somewhat less representative and underlines again the importance of a multivariate analysis that can peel out idiosyncratic effects.

Finally, it is noteable that the number of tables including payments to third party providers has risen, both absolutely and proportionally, since 2005 when that reporting began. Excluding Capital International tables, which never show third party payments, nearly half of the tables received for 2007 included payments to third parties. This increase may point to trustees 


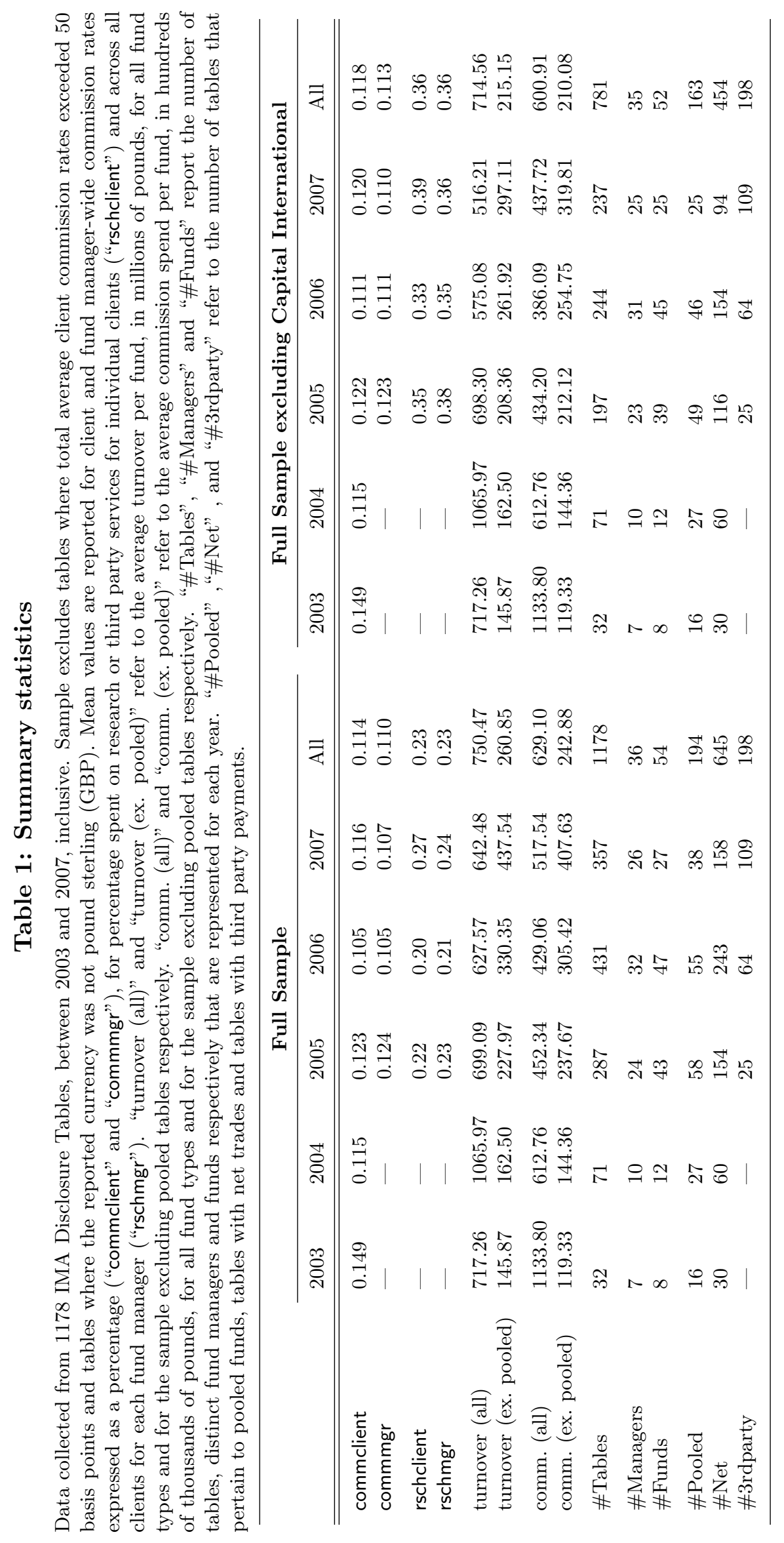


demanding that managers source research not only from brokers but also from independent specialists.

Having scrutinised the data in various univariate ways, the attention is now turned to a multivariate analysis, where factors such as scale, fund manager and fund identity can be controlled for before considering the evolution of commission rates and research/execution splits.

\section{Have commission rates and turnover changed?}

The FSA introduced the final policy statement on bundled brokerage, PS05/9, in July 2005. However, as was described earlier, this came at the end of a long process that stretched as far back as the Myners Report in 2001. By April 2003, the FSA had already begun a consultation process for resolving conflicts in bundled brokerage and had made it clear that changes were going to take place. Between 2003 and 2005 the exact form of the changes became clearer, and from the beginning of 2006 investment managers were expected to produce the new IMA Disclosure Tables for their clients. There was a period of grace until the end of June 2006, during which managers were allowed to continue using legacy systems producing older disclosures if required.

It will not be possible to say with certainty that any changes in commission rates or research/execution splits taking place during the sample period are necessarily due to the changes in regulations by the FSA. However, it is more difficult to discount the impact that these reporting changes had on the investment management community. In fact, it may be argued that these changes were the most significant since Big Bang in 1986 when fixed commissions were abolished in the United Kingdom. Moreover, the 2003-2007 period was characterised by a relatively stable transition from bear to bull market, and did not include sudden market crashes or considerable, exogenous shocks. It is therefore with due caution, but nonetheless some confidence, that we take the position that any significant movements in commission rates or splits during this period are likely to have been at least partially due to the influence of the FSA's regulation reforms.

In this section, two principal analyses are undertaken. First, all observations are employed in a multivariate analysis to determine whether there has been any robust evolution in client commission rates over the sample period. Next, observations drawn from tables in the new IMA 
format are used to examine the main determinants of client commission rates.

\subsection{Have commission rates changed?}

The univariate plots of commission rates suggested that rates may have fallen. Here relevant factors are controlled for to see whether this finding is robust. Regressions of the following type are run, using the method of ordinary least squares with robust standard errors:

$$
\begin{aligned}
\text { commclient }_{i}= & \alpha+\Lambda_{1} \text { Scale }_{i}+\Lambda_{2} \text { Controls }_{i}+\Lambda_{3} \text { Time }_{i}+ \\
& +\Lambda_{4} \text { Manager }_{i}+\Lambda_{5} \text { Fund }_{i}+\epsilon_{i} .
\end{aligned}
$$

The regressions are run across three specifications: (1) full sample, (2) full sample excluding tables produced by Capital International and (3) full sample excluding tables produced by Capital International and any pooled tables. Recall that Capital International constitutes a third of the full sample and may well bias the results; a separate regression is run to capture these effects. Similarly, turnover figures in Table 1 suggested that pooled tables may have different behaviour to bespoke tables; although Regressions (1) and (2) contain a dummy to control for any pooled table effect, Regression (3) is run to check that any findings in (1) and (2) are not driven entirely by the small pooled sub-sample.

Variables in Equation 1 are defined as follows: Scale contains turnover, as defined in Section 4.1. Controls contains net and pooled, while Time contains semi-annual year dummies. Fund manager and public authority fund dummies are included in Manager and Fund respectively.

The main variables of interest here are the semi-annual year dummies, as the determinants of commissions are handled more completely in Section 5.3. The dummy 2003h1, which equals 1 if the observation occurs in the first half of 2003 and zero otherwise, is omitted and so remaining time dummies can be interpreted as being changes in client commission rates relative to this period. The univariate plot of commission rates over time suggests a hypothesis of decreasing commission rates. However, the more rigorous hypothesis is attached to the idea that FSA reforms would be associated with lower commissions. If transparency makes trustees scrutinise the decisions of fund managers more carefully, this may well mean that competitiveness between fund managers takes place not only at the negotiation of the management fee as it did before, but 


\section{Table 2: Client commission rates over time}

The dependent variable is commclient, the rate of commission, expressed in percentage points. Independent variables are as defined in the text. Coefficients are reported with the absolute value of robust $t$ statistics in parentheses, calculated using the method of White (1980). ${ }^{*}$ significant at $5 \%$; ${ }^{* *}$ significant at $1 \%$.

\begin{tabular}{|c|c|c|c|c|}
\hline & & $\begin{array}{c}(1) \\
\text { Full Sample }\end{array}$ & $\begin{array}{c}(2) \\
\text { Full Sample } \\
\text { excl. Capital }\end{array}$ & $\begin{array}{c}(3) \\
\text { Full Sample } \\
\text { excl. Capital \& Pooled }\end{array}$ \\
\hline Scale & turnover & $\begin{array}{l}-0.010 \\
(6.14)^{* *}\end{array}$ & $\begin{array}{l}-0.004 \\
(1.41)\end{array}$ & $\begin{array}{l}-0.005 \\
(1.74)\end{array}$ \\
\hline \multirow[t]{2}{*}{ Controls } & net & $\begin{array}{l}0.008 \\
(2.31)^{*}\end{array}$ & $\begin{array}{l}0.000 \\
(0.01)\end{array}$ & $\begin{array}{l}0.002 \\
(0.35)\end{array}$ \\
\hline & pooled & $\begin{array}{l}0.026 \\
(5.96)^{* *}\end{array}$ & $\begin{array}{l}0.029 \\
(4.36)^{* *}\end{array}$ & - \\
\hline \multirow[t]{10}{*}{$\begin{array}{l}\text { Time } \\
\text { Dummies }\end{array}$} & $2003 \mathrm{~h} 2$ & $\begin{array}{c}-0.012 \\
(0.73)\end{array}$ & $\begin{array}{l}-0.009 \\
(0.57)\end{array}$ & $\begin{array}{l}-0.010 \\
(0.99)\end{array}$ \\
\hline & $2004 \mathrm{~h} 1$ & $\begin{array}{l}-0.028 \\
(1.74)\end{array}$ & $\begin{array}{l}-0.023 \\
(1.50)\end{array}$ & $\begin{array}{l}-0.026 \\
(2.41)^{*}\end{array}$ \\
\hline & $2004 h 2$ & $\begin{array}{l}-0.024 \\
(1.47)\end{array}$ & $\begin{array}{l}-0.017 \\
(1.12)\end{array}$ & $\begin{array}{l}-0.017 \\
(1.46)\end{array}$ \\
\hline & $2005 \mathrm{~h} 1$ & $\begin{array}{l}-0.022 \\
(1.42)\end{array}$ & $\begin{array}{l}-0.019 \\
(1.21)\end{array}$ & $\begin{array}{l}-0.015 \\
(1.54)\end{array}$ \\
\hline & $2005 \mathrm{~h} 2$ & $\begin{array}{l}-0.024 \\
(1.52)\end{array}$ & $\begin{array}{l}-0.025 \\
(1.61)\end{array}$ & $\begin{array}{l}-0.023 \\
(2.36)^{*}\end{array}$ \\
\hline & $2006 h 1$ & $\begin{array}{l}-0.049 \\
(3.07)^{* *}\end{array}$ & $\begin{array}{l}-0.039 \\
(2.48)^{*}\end{array}$ & $\begin{array}{l}-0.033 \\
(3.31)^{* *}\end{array}$ \\
\hline & $2006 h 2$ & $\begin{array}{l}-0.041 \\
(2.54)^{*}\end{array}$ & $\begin{array}{l}-0.044 \\
(2.71)^{* *}\end{array}$ & $\begin{array}{l}-0.042 \\
(3.80)^{* *}\end{array}$ \\
\hline & $2007 \mathrm{~h} 1$ & $\begin{array}{l}-0.042 \\
(2.55)^{*}\end{array}$ & $\begin{array}{l}-0.045 \\
(2.60)^{* *}\end{array}$ & $\begin{array}{l}-0.042 \\
(3.64)^{* *}\end{array}$ \\
\hline & $2007 \mathrm{~h} 2$ & $\begin{array}{l}-0.034 \\
(2.03)^{*}\end{array}$ & $\begin{array}{l}-0.033 \\
(1.93)\end{array}$ & $\begin{array}{l}-0.028 \\
(2.40)^{*}\end{array}$ \\
\hline & constant & $\begin{array}{l}0.370 \\
(16.32)^{* *}\end{array}$ & $\begin{array}{l}0.336 \\
(9.71)^{* *}\end{array}$ & $\begin{array}{l}0.299 \\
(8.96)^{* *}\end{array}$ \\
\hline Fund Manager Dummies & & Yes & Yes & Yes \\
\hline Fund Dummies & & Yes & Yes & Yes \\
\hline Observations & & 1178 & 781 & 618 \\
\hline$R^{2}$ & & 0.45 & 0.52 & 0.51 \\
\hline
\end{tabular}

now also in commission rates on an ongoing basis. This transparency-fulled competition is likely to have the effect of reducing commission rates. The hypothesis is therefore that commission rates have been falling over time.

The results of regressions based on Equation 1 across the three sample specifications are presented in Table 2 in columns (1), (2) and (3) respectively.

Turning first to the time dummies, it is immediately apparent that all dummies are negative 
and, it would appear, that dummies pertaining to later periods are more negative than those for earlier periods. Moreover, this is a pattern that appears to be robust across all three specifications, regardless of whether Capital International tables and pooled tables are excluded or not. It is also true that the significance of the time dummies, while somewhat weak in the early periods, is at least at the $5 \%$ level for all of the results since 2006 bar one. Taken together, this suggests a truly remarkable result, which turns out to be much stronger in the multivariate case than in the univariate: commission rates have broadly been falling since 2003 .

It is somewhat clearer to capture this data graphically, as is done in Figure 6, capturing the output from Table 2 for Regressions (1), (2) and (3).

In this figure, Regression (1) is represented by the solid line, Regression (2) by the dotted line and Regression (3) by the dashed line. The visual representation makes general downward trend clear with an overall downward change of between 3 and 5 basis points, depending on how one choses to interpret the results. ${ }^{15}$ At a conservative 3 basis point reduction, this equates to an annual saving relative to 2003 of some $£ 150000$ in commissions expenditure per public authority on average using 2007 data as discussed above.

One may choose to seek alternative explanations for this decline during the sample period, but it seems the most likely factor would have been the reforms introduced by the FSA during this period. While it is true that this dataset contains only funds associated with public authorities, it is not obvious why the general downward trend in commission should not be more widely applicable. If it is then indeed the case that commission rates are permanently lower by 3 basis points relative to their 2003 levels for all investors, this represents a remarkable victory for the regulator.

\subsection{Has turnover changed?}

The findings and conclusions of the previous section notwithstanding, the claim that regulation has "worked" in this case is somewhat dampened by the recollection that bespoke fund turnover has increased so dramatically as well. While the IMA Disclosure Table focuses the reader's eye on (1) the difference between the commission rate for the trustee's fund and all funds

\footnotetext{
${ }^{15}$ In unreported regressions, the time dummies are replaced with the variable time which takes the number of days since the start of the sample and divides this by 365. As one would expect, this variable is negative and significant across all specifications, with a coefficient that suggests commissions have dropped between 5 and 7 basis points over the sample period.
} 


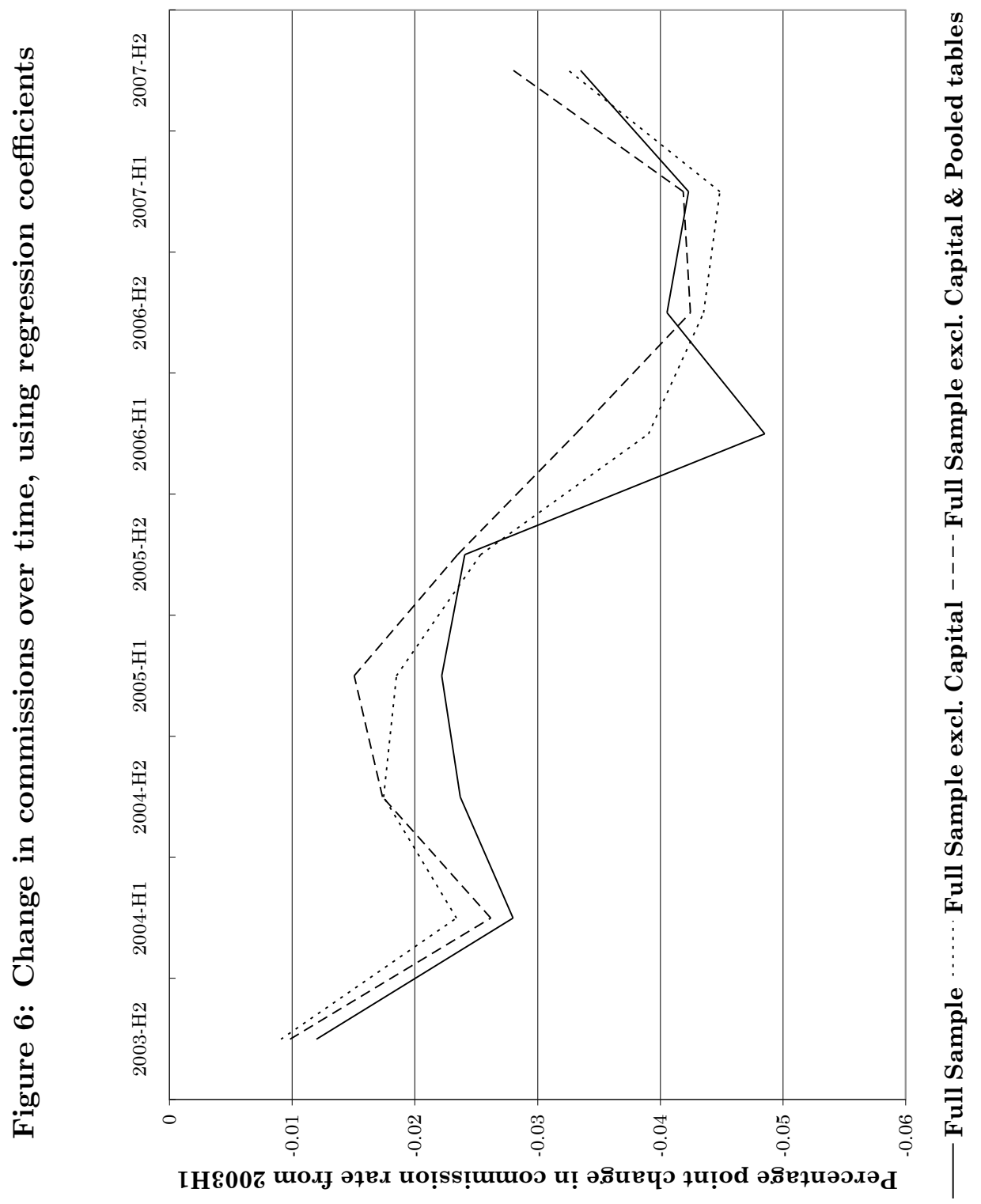


administered by the fund manager, and (2) the difference in research/execution proportion split between the trustee's fund and all the manager's funds, it reports but does not draw attention to the absolute commission spend. Even if commission rates have been falling, as the previous analysis would suggest, given that turnover has simultaneously been increasing by a greater proportion the implication is that the total outflow of money spent on commissions has been increasing, a pattern that was plainly visible in the univariate in Figure 4.

At this stage it is necessary to carry out a few checks to assess the robustness of the univariate finding. The first critique is to point to the composition of the sample, noticing that there are, for example, far more tables in the later years. It may be the case that not all fund managers provided disclosures in the earlier period, meaning that the average turnover for those years would be lower. This is a legitimate criticism but the response is to point to the period where there is an abundance of data, where most disclosures are in the new IMA Disclosure Table format. From 2005 onwards there continues to be a year-on-year increase in turnover of at least $20 \%$. Given that this is a period with substantial coverage, the trend from the early years seems plausible.

The second concern relates to compositional effects. If the churning hypothesis carries any weight, there should be a negative relationship between commission rates and turnover. The analysis above suggests that this is the case, but it may be through the use of averages that a spurious negative correlation between commission rates and turnover is generated. In order to check for this the following procedure was carried out: for each year, total daily turnover and average commission rate values were constructed for each public authority, by fund manager. As an example, for West Sussex County Council, turnover and commission rate values were constructed for Baillie Gifford for years 2003-2006 inclusive and for UBS Global Asset Managers for years 2004-2006 inclusive. This generated 236 "public authority-fund manageryears" for turnover and commissions. Year differences were then constructed, i.e. differences in turnover/commissions by year for instances where the public authority and its particular fund manager had coverage. In the example above, differences would exist for West Sussex and Baillie Gifford for 2003-2004, 2004-2005 and 2005-2006 but only for 2004-2005 and 2005-2006 for West Sussex and UBS. Year-by-year difference regressions and a consolidated regression with year-change dummies were run with the change in commission rate, dcomm, as the explanatory 


\section{Table 3: Changes in turnover and commission rates}

Each observation represents a change in value per public authority-fund manager-year. The dependent variable is dturnover, the year-on-year change in daily turnover, expressed in millions of pounds. The explanatory variable dcomm is the year-on-year change in average client commission rate, expressed as a percentage. Remaining explanatory variables are year-change dummies. Coefficients are reported with the absolute value of robust $t$ statistics in parentheses, calculated using the method of White (1980). ${ }^{*}$ significant at 5\%; ${ }^{* *}$ significant at $1 \%$.

\begin{tabular}{|c|c|c|c|c|c|c|}
\hline & & All Years & '03-'04 & '04-'05 & '05-'06 & '06-'07 \\
\hline $\begin{array}{l}\text { Commission } \\
\text { rate change }\end{array}$ & dcomm & $\begin{array}{l}-6.749 \\
(1.83)\end{array}$ & $\begin{array}{l}-42.049 \\
(3.93)^{* *}\end{array}$ & $\begin{array}{l}16.845 \\
(2.98)^{* *}\end{array}$ & $\begin{array}{l}-13.036 \\
(1.97)\end{array}$ & $\begin{array}{l}-3.436 \\
(1.28)\end{array}$ \\
\hline \multirow[t]{4}{*}{$\begin{array}{l}\text { Year change } \\
\text { dummies }\end{array}$} & d0405 & $\begin{array}{l}0.173 \\
(0.27)\end{array}$ & & & & \\
\hline & d0506 & $\begin{array}{l}-0.286 \\
(0.79)\end{array}$ & & & & \\
\hline & d0607 & $\begin{array}{l}-0.261 \\
(0.71)\end{array}$ & & & & \\
\hline & constant & $\begin{array}{l}0.542 \\
(1.75)\end{array}$ & $\begin{array}{l}0.253 \\
(1.36)\end{array}$ & $\begin{array}{l}0.720 \\
(1.31)\end{array}$ & $\begin{array}{l}0.135 \\
(0.66)\end{array}$ & $\begin{array}{l}0.268 \\
(1.40)\end{array}$ \\
\hline Observations & & 149 & 8 & 14 & 67 & 60 \\
\hline$R^{2}$ & & 0.03 & 0.73 & 0.06 & 0.05 & 0.01 \\
\hline
\end{tabular}

variable for change in daily turnover, dturnover. The results are shown in Table 3.

Both the overall and the year-by-year results deliver the verdict that a negative relationship between changes in turnover and commission rates exists. The overall regression has a dcomm coefficient that is significant at the $10 \%$ level and with the exception of the regression considering the difference between 2005 and 2004, the coefficient of commission rate is always negative for the year-by-year difference regressions, suggesting that the negative relationship is robust after controlling for compositional effects. ${ }^{16}$

The increase in turnover during the sample period remains a puzzling and noteworthy feature. Like much of what is presented in this paper, this finding is sensitive to the particular data sample used in the analysis, which is of course drawn exclusively from public authorities. It is not at all obvious that this finding can be generalised, but it does raise questions about the value-for-money received by public authorities and the ultimate efficacy of the regulation changes for this constituency.

\footnotetext{
${ }^{16}$ The negative relationship appears particularly robust given that the 2003-2004 and 2004-2005 regressions should be treated with some circumspection in light of their very small sample sizes.
} 


\subsection{What determines commission rates?}

Having addressed the evolution of commission rates over time using all available data, the attention is now turned to the later, richer dataset of new IMA Disclosure Tables. The new IMA format allows for an analysis of the determinants of commission rates because it includes a number of additional variables that, a priori, would seem to be significant candidates.

To carry out this analysis, three regressions are run according to this equation, using ordinary least squares with robust standard errors:

$$
\begin{aligned}
\operatorname{commclient}_{i}= & \alpha+\Lambda_{1} \text { MgrPolicy }_{i}+\Lambda_{2} \text { SoftComm }_{i}+ \\
& +\Lambda_{3} \text { Scale }_{i}+\Lambda_{4} \text { Controls }_{i}+ \\
& +\Lambda_{5} \text { Time }_{i}+\Lambda_{6} \text { Manager }_{i}+\Lambda_{7} \text { Fund }_{i}+\epsilon_{i} .
\end{aligned}
$$

For this section the variables of particular interest are contained in MgrPolicy (commmgr) and SoftComm (rschclient and 3rdparty), but given that they have not yet been discussed, the variables in Scale and Controls, which were briefly introduced before, should also receive some attention. The univariate plot suggested that client commission rates closely track managerwide commission rates, so commmgr is expected to be a positive determinant. Furthermore, given that research is more expensive than execution, it is expected that higher proportions spent on research will accordingly be associated with higher commissions; again, a positive coefficient is predicted for rschclient. The expectation is that independent research will be more expensive than the bundled sell-side research received from the executing broker: 3rdparty is expected to have a positive coefficient. Finally, economies of scale suggest that turnover should be negative; net should theoretically have no effect (it is not clear why the presence of net trades should affect the commission rate charged on trades subject commissions); and pooled is expected to have a positive coefficient as pooled funds seem to be used by public authorities as a way of obtaining exposure to overseas markets, which are likely to have higher commission rates as per the argument advanced on page 26 .

The results for regressions run across the three sample specifications for Equation 2 are contained in Table 4. 


\section{Table 4: Determinants of client commission rates}

The dependent variable is commclient, the rate of commission, expressed in percentage points. Independent variables are as defined in the text. Coefficients are reported with the absolute value of robust $t$ statistics in parentheses, calculated using the method of White (1980). * significant at $5 \%$; ${ }^{* *}$ significant at $1 \%$.

\begin{tabular}{|c|c|c|c|c|}
\hline & & $\begin{array}{c}(4) \\
\text { Full Sample }\end{array}$ & $\begin{array}{l}(5) \\
\text { Full Sample } \\
\text { excl. Capital }\end{array}$ & $\begin{array}{c}(6) \\
\text { Full Sample } \\
\text { excl. Capital \& Pooled }\end{array}$ \\
\hline $\begin{array}{l}\text { Manager } \\
\text { Policy }\end{array}$ & commmgr & $\begin{array}{l}0.760 \\
(11.51)^{* *}\end{array}$ & $\begin{array}{l}0.689 \\
(9.30)^{* *}\end{array}$ & $\begin{array}{l}0.720 \\
(6.74)^{* *}\end{array}$ \\
\hline \multirow[t]{2}{*}{$\begin{array}{l}\text { Soft } \\
\text { Commissions }\end{array}$} & rschclient & $\begin{array}{l}0.083 \\
(4.56)^{* *}\end{array}$ & $\begin{array}{l}0.087 \\
(4.70)^{* *}\end{array}$ & $\begin{array}{l}0.072 \\
(2.66)^{* *}\end{array}$ \\
\hline & 3rdparty & $\begin{array}{l}-0.006 \\
(1.03)\end{array}$ & $\begin{array}{l}-0.007 \\
(1.09)\end{array}$ & $\begin{array}{l}0.003 \\
(0.37)\end{array}$ \\
\hline Scale & turnover & $\begin{array}{l}-0.007 \\
(3.60)^{* *}\end{array}$ & $\begin{array}{l}-0.008 \\
(2.27)^{*}\end{array}$ & $\begin{array}{l}-0.010 \\
(2.61)^{* *}\end{array}$ \\
\hline \multirow[t]{3}{*}{ Controls } & net & $\begin{array}{l}0.006 \\
(1.94)\end{array}$ & $\begin{array}{l}0.002 \\
(0.42)\end{array}$ & $\begin{array}{l}0.001 \\
(0.28)\end{array}$ \\
\hline & pooled & $\begin{array}{l}0.008 \\
(1.10)\end{array}$ & $\begin{array}{l}0.010 \\
(1.29)\end{array}$ & - \\
\hline & constant & $\begin{array}{l}0.088 \\
(2.71)^{* *}\end{array}$ & $\begin{array}{l}0.079 \\
(1.29)\end{array}$ & $\begin{array}{l}0.223 \\
(3.24)^{* *}\end{array}$ \\
\hline Time Dummies & & Yes & Yes & Yes \\
\hline Fund Manager Dummies & & Yes & Yes & Yes \\
\hline Fund Dummies & & Yes & Yes & Yes \\
\hline Observations & & 851 & 488 & 395 \\
\hline$R^{2}$ & & 0.65 & 0.68 & 0.71 \\
\hline
\end{tabular}

In keeping with the evidence presented in the univariate graphs, commmgr enters with a positive and highly significant coefficient. The suggestion is that the commission rate charged by the manager, on average, is the primary determinant of the commission rate charged to any of its clients. This is probably not surprising given that (1) the client's commission rate is contained within the average rate and (2) some managers separate "average manager-wide" rates by mandate so that a fund investing specifically in UK equities, for instance, is given a comparator for funds administered by the manager that only invest in UK equities. What is interesting is that funds of public authorities appear to be charged 20-30\% less, after controlling for scale and other factors, than average funds. However, it remains unclear why this favouritism occurs; is it because these are particularly large funds, or are better managed by their trustees, or because they are public?

As expected, rschclient enters with a positive and highly significant coefficient as well. Given 
that research is expensive, if the proportion spent on research increases, one would expect a corresponding increase in commission rate charged for that associated trade. Notably, though, it does not seem to make any difference whether this research is provided by the executing broker or whether it comes via independent third parties. The coefficients of 3rdparty are neither statistically nor economically significant, suggesting that fund managers should feel free to choose the most appropriate source of research without having to worry about price considerations.

In keeping with the previous regressions, turnover enters with a negative and significant coefficient, suggesting that economies of scale are present. The presence of net trades has no effect in regressions where Capital International is excluded; the nearly significant and positive coefficient in Regression (4) is puzzling as it suggests that-for Capital International-when there are net trades, the remaining trades are charged at a higher commission rate. Finally, pooled funds are associated with higher commissions, but the effect is not significant; this suggests that the significance of this variable in earlier regressions may have been driven by the earlier (2003-2004) period.

\section{$6 \quad$ Has the split between research and execution changed?}

Thus far the attention has been largely focused on commission rates. Recall, though, that the original impetus for regulation change in bundled brokerage came from the Myners Report in 2001 that flagged the conflicts of interest inherent in this aspect of institutional investment in the United Kingdom. Specifically, the concern was that fund managers were extracting goods and services from brokers as part of bundled brokerage that did not necessarily benefit their clients, even though those clients paid for the goods and services. The new IMA Disclosure Table mandates that managers declare how they have allocated the commissions of clients between execution and research. In the following section, the determinants of this split as well as its evolution since 2005 are addressed in a multivariate regression analysis.

For this analysis, three regressions are run according to the following equation, using ordinary least squares with robust standard errors:

$$
\text { rschclient }_{i}=\alpha+\Lambda_{1} \text { MgrPolicy }_{i}+\Lambda_{2} \text { Scale }_{i}+\Lambda_{3} \text { Controls }_{i}+
$$




$$
+\Lambda_{4} \text { Time }_{i}+\Lambda_{5} \text { Manager }_{i}+\Lambda_{6} \text { Fund }_{i}+\epsilon_{i} .
$$

Variables are as defined previously, however in this case MgrPolicy contains not only commmgr but also rschmgr, the proportion spent on research for the fund manager, averaged across all its clients for the reporting period. Particularly given the findings of Section 5.3 with respect to commmgr, the expectation for this variable is to have a positive coefficient, though it is not clear whether it should be greater than or less than 1.

A more definite hypothesis can be drawn with respect to the time dummy variables. Given that the aim of the regulation has been to shine a light on the split between execution and research, the expectation here is that managers will have reduced the proportion spent on research, after controlling for other factors. This would also be consistent evidence presented for falling commission above.

The results for the regressions described in Equation 3 are presented in Table 5.

Considering the determinants first before looking at time variation, it is clear that just as commmgr was a significant determinant of commclient, rschmgr is a highly significant and positive determinant of rschclient. In fact, there is almost a one-to-one correspondence between the variables: a one percentage point change in manager-wide split is associated with only slightly less than a one percentage point change in the client split. However, in addition to this component of manager policy, it turns out that the commission rate charged by managers on average is a positive and significant determinant of how much is spent on research, client by client. This makes sense: if managers are expensive, chances are that it is because they are spending more on research than execution than their cheaper competitors.

Interestingly, larger trading volumes tend to be associated with higher execution proportions, suggesting that managers may be employing a rule where reasonably fixed pound amounts are spent on research instead of using a proportion rule. One can understand that this may be the case: there is almost certainly a point of satiation regarding research so that if one is splitting the commissions of a very large trading volume, one would elect to spend a smaller proportion on research than if the trading volume were less.

Turning to the time variation, the dummy variables tell an extraordinary story. Far from the expectation that the split would have reduced over time, it has increased, with increases being associated with strong statistical significance across all specifications. The time dummy 


\section{Table 5: Research determinants with time components}

The dependent variable is rschclient, the proportion of commissions that is not spent on execution by the executing broker. Independent variables are as defined in the text. Coefficients are reported with the absolute value of robust $t$ statistics in parentheses, calculated using the method of White (1980). ${ }^{*}$ significant at $5 \%$; ${ }^{*}$ significant at $1 \%$.

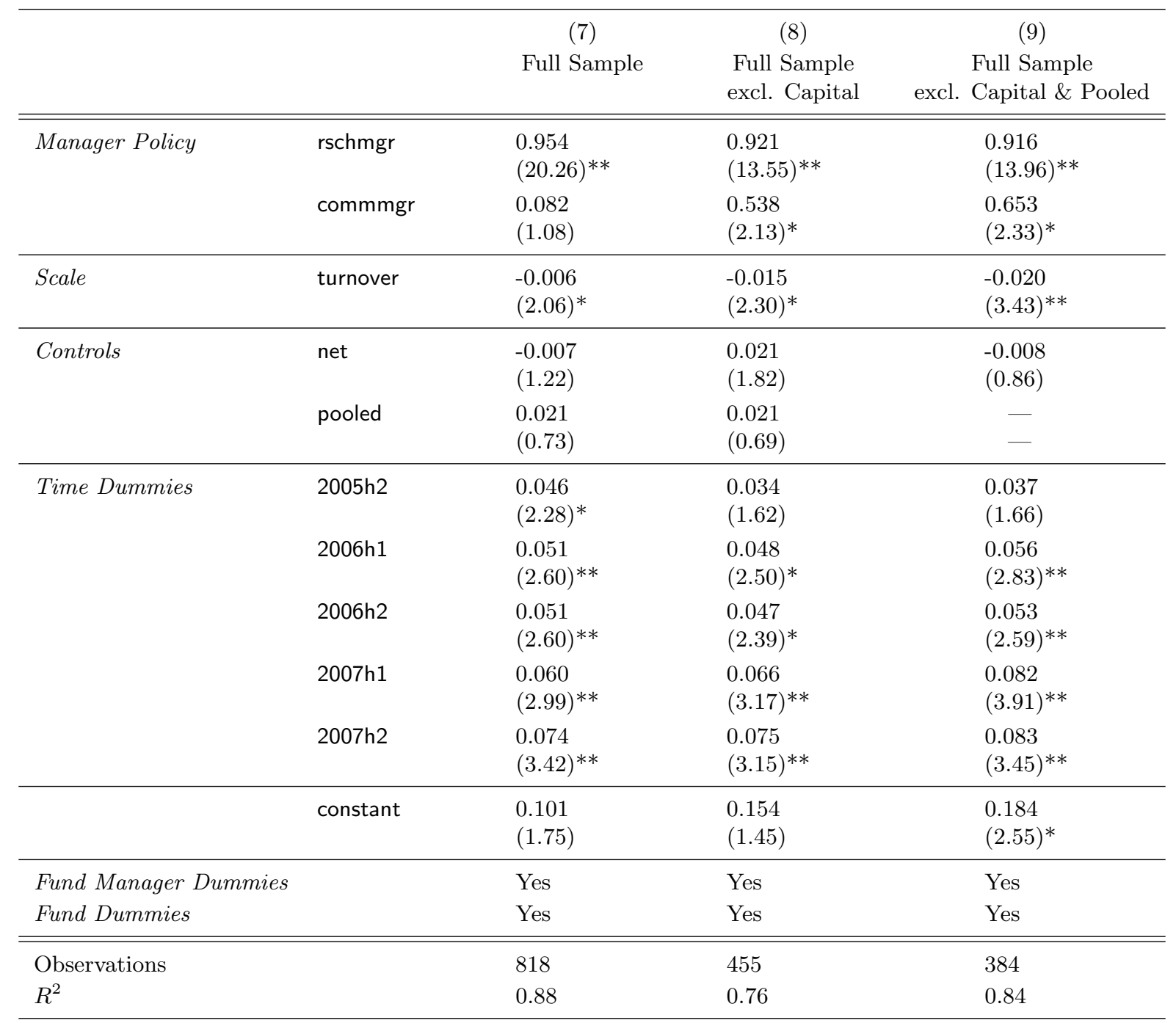

coefficients are graphed in Figure 7, which should be interpreted as showing the change in proportion spent on research, relative to the first half of 2005.

That this graph charts such a definite increase in proportion spent on research, when the univariate figure showed no particular pattern, serves as a reminder that controlling for relevant factors in a multivariate analysis is crucial. The upward trend runs absolutely against the natural hypothesis described before. It is difficult to say exactly what is driving this result, though there are a few possible explanations that are consistent with the finding. 


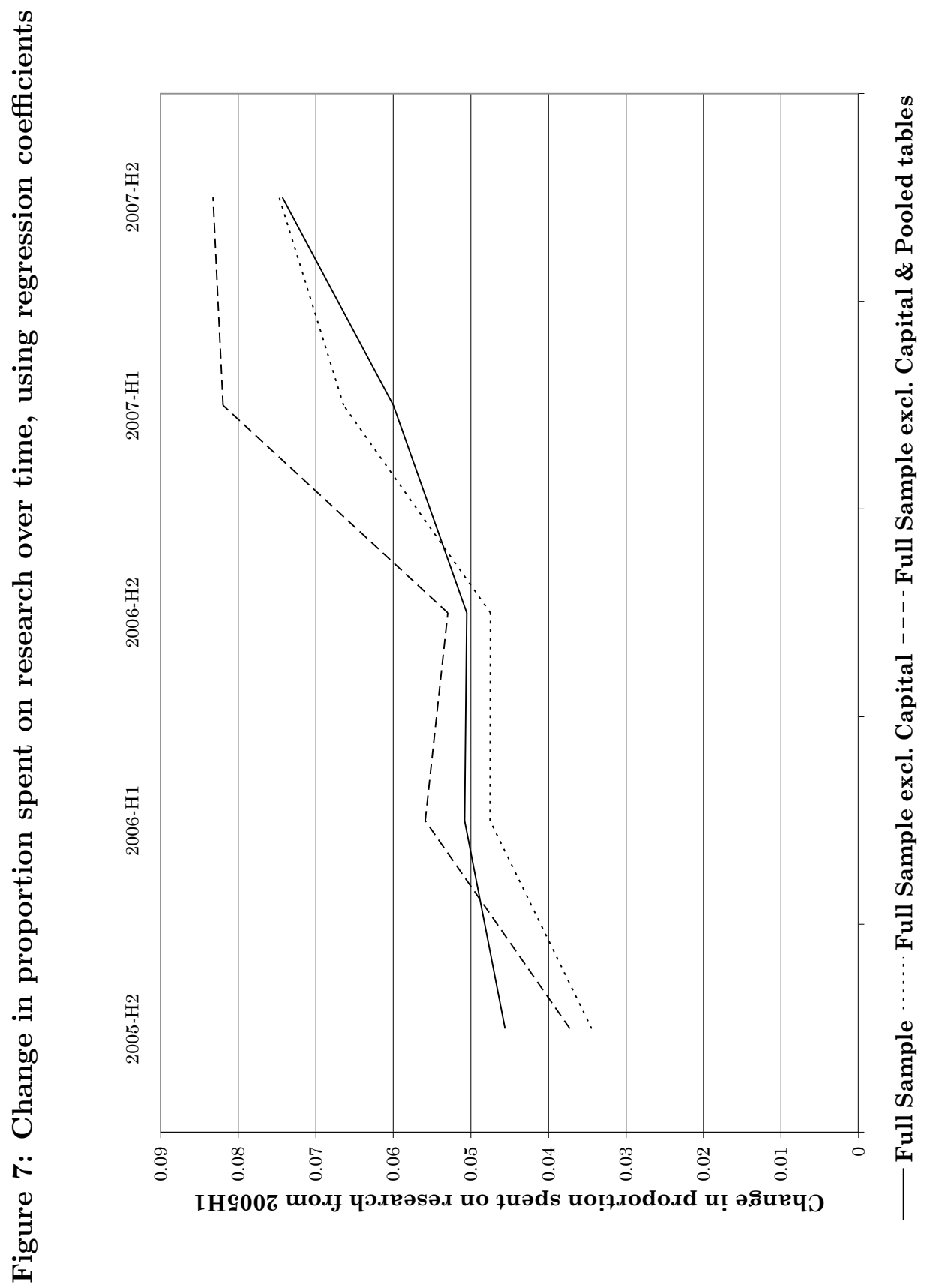


The first of these, which is associated with regulatory success and has some anecdotal support, assumes that managers have been feeling the pressure to report the split more accurately because of questions asked by trustees at quarterly or semi-annual meetings. Whereas previously managers were able to "get away" with either not reporting a split or just reporting a "notional" split, pressure to report more accurately has resulted in what appears to be an increase in commissions spent on research. That the split is being reported more accurately can be interpreted as a positive consequence following from the FSA reforms.

A less benign explanation, also consistent with the evidence, suggests that in the face of falling commission rates due to the FSA-induced increased transparency, brokers have put pressure on managers to buy more research to maintain a relatively constant income for sellside research departments. This explanation, like the churning hypothesis advanced earlier, favours conflicts of interest and suggests that superficial indicators of regulatory success like falling commission rates are potentially misleading.

\section{Conclusions}

After controlling for relevant factors in a multivariate setting, commission rates seem to have fallen between 2003 and 2007 while the proportion spent on research instead of execution has risen. Although it is not possible to attribute these movements to any particular cause, arguably the most important institutional change for asset management during this period has been the discussions and subsequent introduction of regulations by the FSA to increase transparency and thereby reduce conflicts of interest. This was done primarily through the introduction of a new, standardised receipt design that fund managers produce for their clients on a regular basis: the IMA Disclosure Table.

Having obtained the unique dataset of IMA Disclosure Tables for this project using the Freedom of Information Act (2000) and Freedom of Information (Scotland) Act (2002) in what constituted a data gathering process of two years, these commission rate and research/execution split findings provide the first quantitative and representative analysis of investment management in the United Kingdom around this important period. The relevance of the results extends

beyond academia to investment managers, brokers, fund trustees, the FSA, foreign regulators concerned with bundled brokerage solutions as well as the general public, whose money is at 
stake in this dataset of public authority funds.

That commission rates have fallen may be characterised as a triumph for regulation, as may the apparent increase in proportion spent on research if this latter finding is associated with improved and more honest reporting. The data analysis has also revealed the considerable effect that fund manager policy has on the treatment received by particular clients.

However, much of what has been reported in the more sophisticated analysis is somewhat overshadowed by the extraordinary finding that, for this dataset at least, turnover and money spent on commissions has more than doubled between 2003 and 2007. If this is in fact a robust and generalisable result, it provides an indictment of the FSA's focus on rates and proportions in the new IMA Disclosure Table format. Could it be that managers and brokers have responded to the regulatory pressures by lowering commission rates but more than proportionally increasing turnover to retain profitability?

What does seem clear from the findings presented in this paper is that the regulations, while possibly successful in some respects, have not delivered a panacea. The next step must surely be to obtain additional IMA Disclosure Tables, preferably from sources other than public authorities, so that a longer time series and more representative sample may be used to test hypotheses. In the meantime, trustees of public authorities should perhaps begin by asking their investment managers to explain why there has been an apparent need to double, or even treble, turnover in recent years. 


\section{References}

Armstrong, M. (2006), 'Recent developments in the economics of price discrimination', in R. Blundell, W. K. Newey and T. Persson, eds, Advances in economics and econometrics: Theory and applications, Cambridge University Press, Cambridge.

Bakos, Y. And Brynjolfsson, E. (1999), 'Bundling information goods: Pricing, profits, and efficiency', Management Science, 45 (12), 1613-1630.

Bakos, Y., Lucas, H. C., Oh, W., Simon, G., Viswanathan, S. and Weber, B. W. (2005), 'The impact of e-commerce on competition in the retail brokerage industry', Information Systems Research, 16 (4), 352-371.

Barber, B. M., Lehavy, R. and Trueman, B. (2007), 'Comparing the stock recommendation performance of investment banks and independent research firms', Journal of Financial Economics, 85 (2), 490-517.

Blume, M. E. (1993), 'Soft dollars and the brokerage industry', Financial Analysts Journal, 49 (2), 36-44.

Burstein, M. (1960), 'The economics of tie-in sales', The Review of Economics and Statistics, $42(1), 68-73$.

Byrne, A., Lawson, N., Phillipson, R. and Vincent-Silk, C. (2005), 'Research reshaped', Investit Intelligence research paper.

Conrad, J., Johnson, K. And Wahal, S. (2001), 'Institutional trading and soft dollars', Journal of Finance, 56 (1), 397-416.

DiNG, F. (2007), 'Brokerage commissions, perquisites, and delegated portfolio management', Working Paper, Hong Kong University of Science \& Technology.

Geng, X., Stinchcombe, M. B. And Whinston, A. B. (2005), 'Bundling information goods of decreasing value', Management Science, 51 (4), 662-667.

Greenwich Associates (2006), 'Bundled brokerage and soft commissions: Institutional plans, practices, and perspectives from the U.K.', Greenwich Associates research report.

Groysberg, B., Healy, P., Chapman, C., Shanthikumar, D. and Gui, Y. (2007), 'Do buy-side analysts out-perform the sell-side', Working Paper, Harvard University and University of North Carolina, Chapel Hill.

Horan, S. And Johnsen, D. (2008), 'Can third-party payments benefit the principal? The case of soft dollar brokerage', International Review of Law and Economics, 28 (1), 56-77.

KhÜN, K.-U. And Vives, X. (1995), 'Information exchanges among firms and their impact on competition', Technical Report, Office for Official Publications of the European Communities, Luxembourg.

Livne, G. And Trueman, B. (2002), 'The impact of soft dollars on market equilibrium and investors' profits', Working Paper, London Business School and University of California, Berkeley.

Myners, P. (2001), 'Institutional investment in the United Kingdom: A review', Report commissioned by HM Treasury. 
OxerA (2003), 'An assessment of soft commission arrangements and bundled brokerage services in the UK', Report commissioned by Financial Services Authority.

Oxera (2006), 'Soft commissions and bundled brokerage services: post-implementation review', Report commissioned by Financial Services Authority.

Schultz, C. (2005), 'Transparency on the consumer side and tacit collusion', European Economic Review, 49 (2), 279-297.

Schwartz, R. A. And Steil, B. (2002), 'Controlling institutional trading costs', Journal of Portfolio Management, 28 (3), 39-49.

White, H. (1980), 'A heteroskedasticity-consistent covariance matrix estimator and a direct test for heteroskedasticity', Econometrica, 48, 817-838. 